Wilson, R. E., Gosling, S. D., \& Graham, L. T. (in press). A Review of Facebook Research in the Social Sciences. Perspectives on Psychological Science.

A Review of Facebook Research in the Social Sciences

Robert E. Wilson

Washington University in St. Louis

Samuel D. Gosling \& Lindsay T. Graham

University of Texas, Austin

Robert E. Wilson, Department of Psychology, Washington University in St. Louis

Samuel D. Gosling, and Lindsay T. Graham, Department of Psychology, The University of Texas at Austin.

We are grateful to Mario Alvarado, Erica Baranski, Natasha Ghosh, Sami Herin, Lucy, Lui, Mustafa Moon, and Jeanette Orozco for their help as research assistants during the literature review.

Correspondence concerning this article should be addressed to Robert E. Wilson, Psychology Building, Campus Box 1125, 1 Brookings Drive, St. Louis, MO 63130. E-mail: robertwilson@go.wustl.edu 


\begin{abstract}
With over 800 million active users, Facebook is changing the way hundreds of millions of people relate to one another and share information. A rapidly growing body of research has accompanied the meteoric rise of Facebook as social scientists assess the impact of Facebook on social life. In addition, researchers have recognized the utility of Facebook as a novel tool to observe behavior in a naturalistic setting, test hypotheses, and recruit participants. However, research on Facebook emanates from a wide variety of disciplines with results being published in a broad range of journals and conference proceedings, making it difficult to keep track of various findings. And because Facebook is a relatively recent phenomenon, there still exists uncertainty about the most effective ways to do Facebook research. To address these issues, we conducted a comprehensive literature search, identifying 410 relevant articles, which we sorted into five categories: Descriptive analysis of users, motivations for using Facebook, identity presentation, the role of Facebook in social interactions, and privacy and information disclosure. The literature review serves as the foundation from which we assess current findings and offer recommendations to the field for future research on Facebook and online social networks more broadly.
\end{abstract}

Keywords: Facebook, online social network, social networking sites, social network analysis, privacy, motivation, identity presentation 


\section{A Review of Facebook Research in the Social Sciences}

The sheer online ubiquity of Facebook is astounding. As of February 2012, Facebook has over 845 million users (more than the population of Europe) who spend more than 9.7 billion minutes per day on the site (Facebook, 2012; Rusli, 2012; for a description of Facebook, see Appendix A). Users share 4 billion pieces of content per day, including uploads of 250 million photos, and Facebook is now integrated with over seven million websites and applications (Facebook, 2012; Tsotsis, 2011). In March of 2010, Facebook passed Google to become the most visited website in the U.S., accounting for 7.07\% of all U.S. web traffic (Dougherty, 2010). And Facebook's dominance extends well beyond United States, with over $80 \%$ of current users residing outside of the U.S. (Facebook, 2012). Despite having only about 3,000 employees worldwide, Facebook is valued at around \$100 billion U.S. dollars (Facebook, 2012; Gertner, 2011; Siegler, 2011, Swartz, 2012). In short, since its creation in February of 2004, Facebook has become a spectacular success by creating a massive new domain in which millions of social interactions are played out every day. This burgeoning new sphere of social behavior is inherently fascinating but it also provides social scientists with an unprecedented opportunity to observe behavior in a naturalistic setting, test hypotheses in a novel domain, and to recruit participants efficiently from many countries and demographic groups.

As researchers scramble to keep up with the rapid evolution of Facebook in terms of size, features, and policies, we assess the degree to which social scientists have been successful in illuminating the psychological and sociological processes associated with this online social network (OSN). Our original goal was to review all articles ever written about Facebook and produce a neat summary of what the findings to date have taught us. However, we soon discovered that despite there being a sizeable body of research on Facebook, the questions, 
methods, and perspectives were so diverse and fragmented that it would be impossible to write a coherent summary of the literature. But we also realized that without summarizing the current trends in the literature - fragmented though they are - the situation was unlikely to improve. So we reviewed the literature and used it as the launching point for a broader examination of bestpractice methods as well as a consideration of promising directions for future research. The current article is the result.

As this paper will show, there has been major progress towards analyzing behavior on Facebook and effectively utilizing Facebook as a research tool. However, there is much variability in the quality of research. Our comparative analyses identified a number of obstacles impeding research on Facebook and served as the foundation for specifying some robust research methods and best-practice recommendations in this and related domains.

\section{Why study Facebook?}

There are three broad reasons why Facebook is of relevance to social scientists. First, activities performed on Facebook (e.g., connecting to others, expressing preferences, status updates) can leave a wealth of concrete, observable data in their wake. Therefore, the domain provides many new opportunities for studying human behavior that previously had to rely on behaviors that were difficult to assess (e.g., making friends, chatting). Social scientists are sometimes accused of failing to examine actual behavior, relying instead on hypothetical or retrospective self-reports of behavior (Baumeister, Vohs, \& Funder, 2007; Furr, 2009); behavioral residue left on Facebook provides a compelling source of measurable behavior traces (Graham, Sandy, \& Gosling, 2011; Webb, Campbell, Schwartz, Sechrest, \& Grove, 1981). It is useful to think of Facebook as an ongoing database of social activity with information being added in real time. As we discuss below, Facebook is popular across a broad swathe of 
demographic groups and in many different countries so it offers a unique source of information about human behavior with levels of ecological validity that are hard to match in most common research settings. Thus, topics that have long been of interest to social scientists, such as how people become acquainted, how social networks spread, and how people communicate their identities, can be examined in this new context.

Second, the tremendous popularity of Facebook makes it a topic worthy of study in its own right. Facebook and other OSNs are interesting to social scientists because in addition to reflecting existing social processes they are also spawning new ones by changing the way hundreds of millions of people relate to one another and share information. Some commentators describe OSNs as a medium that is disconnected from the "real world," but this stance creates a false distinction; for vast numbers of people living in industrialized societies, OSNs have become a core feature of daily life such that their online and offline worlds have become at least partially integrated (Lampe, Ellison, \& Steinfield, 2006). Therefore, if social scientists hope to fully understand social life in contemporary contexts, they must examine OSNs. Facebook is by far the most popular OSN (Kreutz, 2009) making it the logical place to begin investigating the patterns, causes, and consequences of the social processes associated with OSN usage.

Third, the rise of OSNs brings both new benefits and dangers to society, which warrants careful consideration. The benefits associated with Facebook, such as the strengthening of social ties, are tempered by concerns about privacy and information disclosure. As Facebook becomes increasingly integrated into everyday life, it becomes necessary to monitor and examine the platform's positive and negative impacts on society.

\section{Who Studies Facebook?}

Scholars from a wide variety of disciplines - ranging from law, economics, sociology, 
and psychology, to information technology, management, marketing, and computer-mediated communication - have recognized the importance of Facebook. As a consequence of their distinct disciplinary affiliations and research goals, these efforts at understanding Facebook have followed largely independent paths and have been published in a broad range of journals and conference proceedings. The result is an impressive collection of research, but the fragmented literature makes it difficult to keep track of the various findings. Each of the discipline-bound studies is interesting and valuable in its own right, but provides only narrow windows into what is known about Facebook. In addition, articles are being published in a wide range of international journals and conference proceedings, many of which are not found in the databases traditionally monitored by social scientists. In fact, in the course of preparing this review, even after scouring several databases (e.g., PsycInfo, Google Scholar, and Web of Science) for relevant reports, we had not discovered the many pertinent reports listed only in the computerscience oriented IEEE Xplore database.

Articles on OSNs vary dramatically in the breadth of their focus. Some articles focus exclusively on Facebook whereas others include other OSNs, too. A broad focus can be useful in identifying general patterns but there are dangers in treating OSNs as a single general category without drawing distinctions among them. For example, in one article participants needed only to be a member of any OSN to qualify for inclusion in a study that explored what motivated older adolescents to use OSNs (Barker, 2009). In this study, only 54\% of participants used Facebook, while the rest qualified for the study because they were members of MySpace, Friendster, or another OSN. Results were framed in terms of OSNs generally and provided valuable insight into the motivations of older adolescent OSN use. However, the findings blurred potentially consequential distinctions across OSNs in terms of OSN-specific demographics, functionality, 
and network development. Therefore, in our review we omitted articles that broadened their scope to OSNs in general without reporting results specific to Facebook (see boyd \& Ellison, 2007 for an excellent review of all OSNs).

So just as political scientists or economists may sometimes find it useful to study Asia as a whole (e.g., lumping China together with Taiwan, Singapore, etc.), for many questions it makes sense to study the individual countries separately, especially when one of them (e.g., China) dominates a space. This approach allows researchers to document and understand the diverse processes that operate within that country; of course, those country-specific findings can later be linked to findings from other countries and the region as a whole. Based on this reasoning, we narrowed our scope to Facebook, the currently dominant OSN, with the hope that our detailed summary of research will both illuminate Facebook-specific phenomena and enrich knowledge about OSNs more generally. We encourage researchers to include multiple OSNs in their studies but we recommend reporting the results separated by each OSN to clarify the effects that are OSN-specific and those that generalize across OSNs.

The aims of the present paper are to summarize what has been found in regards to Facebook, pinpoint the major gaps in knowledge in this domain, provide recommendations for research practice, and identify promising directions for future research on Facebook and OSNs more broadly.

\section{Literature Review}

This is the first major review devoted to academic articles written about Facebook, so we cast a broad net. The focus of the review was on empirical articles published in academic journals or conference proceedings that explicitly studied Facebook. To be included as relevant in our final review, a source must have: (1) specifically investigated Facebook (but not 
necessarily only Facebook) and, if other OSNs were included, reported data separately for Facebook, (2) been published in a peer-reviewed academic journal or peer-reviewed conference proceedings, and (3) reported empirical findings.

\section{Limitations of the Search Criteria}

By including only those reports that specifically investigated Facebook, it is likely that we omitted some articles that discussed online social networking in general. Our rationale for excluding broader articles on OSNs was based on conceptual and practical considerations. Other OSNs, such as MySpace, Xt3 (a Catholic OSN site), LinkedIn, and FourSquare, have varied histories and are associated with different patterns of use, user characteristics, and social functions compared with Facebook. Therefore, it would have been conceptually unwarranted to apply conclusions derived from OSN research in general to the specific case of Facebook. In addition, we chose to exclude non-Facebook articles because they would have distended our bibliography to an unmanageable number of articles, making a concise and informative review of articles impractical.

In choosing to include only peer-reviewed academic articles, sources such as unpublished manuscripts, dissertations, position papers, and popular press articles were omitted. Many of these sources offered thoughtful insights as well as ideas for future research. However, many other such sources report research with sub-optimal designs, inappropriate analyses, and unwarranted conclusions. The main goal of our review was to gather high-quality research about Facebook. Without setting the standard to include only peer-reviewed research, it would have required making arbitrary decisions about which non-peer-reviewed articles were of sufficient quality to be included in our review.

Our third criterion required each article to be empirically based, which resulted in the 
exclusion of commentaries, reviews, proposals, and popular press articles that did not use empirical data to support their reasoning. This final criterion was a safeguard against unsubstantiated conjecture.

Despite their drawbacks, we believe the three criteria provide a sensible and effective system for gathering relevant research. We hope that the bibliography produced using these criteria (see Appendix B) will function as a valuable resource to those conducting research on Facebook in the future. The set of articles reported in Appendix B formed the empirical basis for our analyses of the Facebook literature but, of course, in the text below we do draw on articles beyond that set when relevant (e.g., articles published in 2012, articles on OSNs that do not report separate Facebook results). And not every article identified in the literature search (and listed in Appendix B) is referenced individually in the text of the paper. Thus, the references section and Appendix B overlap only partially.

\section{Literature Search procedures}

Our literature search procedures (described in detail in the online supplementary materials) used two basic steps: Generating a large pool of potentially relevant articles and then selecting a smaller subset of articles deemed relevant based on the three inclusion criteria described above. The search was completed on January 1st, 2011. As shown in Figure 1, 223 articles meeting our criteria were published by this date.

\section{Survey of Facebook Research}

In this section, we summarize the themes and findings of research that emerged from our review of the literature. To identify the major topic areas by which to organize our review, we undertook a systematic series of theme-extraction procedures commonly used in qualitative research (Braun \& Clarke, 2006). Specifically, to ensure the themes extracted were not overly 
biased by the idiosyncratic perspective of any single researcher, a team of nine researchers conducted independent literature reviews and then together generated a list of the major themes that emerged from the literature. This process resulted in the identification of five general categories that captured the major themes found throughout the literature: Descriptive analysis of users, motivations for using Facebook, identity presentation, the role of Facebook in social interactions, and privacy and information disclosure. The five categories correspond to five broad questions: (1) Who is using Facebook and what are users doing while on Facebook? (2) Why do people use Facebook? (3) How are people presenting themselves on Facebook? (4) How is Facebook affecting relationships among groups and individuals? And (5) why are people disclosing personal information on Facebook despite potential risks?

For the sake of clarity, articles were assigned to only a single category; if the content of articles fell into more than one category it was placed into the one that was most relevant (see Table 1). Thus, the category sizes should be seen as indicative of each article's primary topic, not necessarily as its only one. Moreover, despite the care we took in deriving the categories, we do not view them as definitive. They were chosen to serve as a useful organizational framework that seemed to reflect the trends that could be discerned in the Facebook research literature at that time.

As noted above, the five categories were derived from an analysis of the articles identified by January $1^{\text {st }}, 2011$. However, it was another whole year before this paper was written and accepted for publication. To provide the most up-to-date summary of articles and also to test the applicability of our categorization system, we repeated our review procedures for 2011 to include all articles (meeting our criteria) published up until January $1^{\text {st }}, 2012$. The review of 2011 yielded 187 more articles and conference papers, bringing the new total to 410 . 
Reassuringly, our five-category system effectively accommodated all the new reports. The review below and the bibliography in the online supplement incorporate the full dataset, including the reports from 2011.

\section{Who is Using Facebook?}

To appreciate the form and functions of Facebook, it is helpful to understand its rapid expansion. So before reviewing the findings to emerge from the descriptive analyses of Facebook users, we start with a short summary of Facebook's history and growth.

In February of 2004, Mark Zuckerberg created Facebook (then called "thefacebook") in his dorm room at Harvard University (Markoff, 2007). Within one month of its creation, half of the Harvard student population had signed up (Phillips, 2007). Facebook quickly expanded the list of approved networks, allowing it to reach a wider range of users. By 2005, Facebook allowed access to over 800 college and university networks as well as high-school networks (Arrington, 2005). In 2006, Facebook continued to expand its network base, allowing access to over 22,000 commercial organization networks (Zywica \& Danowski, 2008). The last major network expansion occurred in 2006, which allowed access to anyone over the age of thirteen with a valid email address (Brown, 2008). As shown in Figure 1, the rapid expansion of approved networks was followed by a dramatic rise in user growth.

Even with such incredible success, the growth of Facebook shows little sign of abating. By expanding globally as well as attracting a wider range of age groups, Facebook has been able to continue its rapid growth. Facebook originated in the United States but more than $80 \%$ of current Facebook users now live outside the United States and the majority of new growth is occurring internationally, with Facebook available in over 70 languages (Facebook, 2012; Schonfeld, 2010). In addition to the growing global diversity of users, the typical age of 
Facebook users has also shifted over the course of the network's growth. For example, Facebook originally targeted college-aged students but in 2010 the fastest growing demographic group was users over the age of 34 , representing $28 \%$ of users (Fletcher, 2010).

Descriptive analyses of users. When users register for Facebook, they must agree to the terms of service, which includes the provision that Facebook Inc. has the right to collect users' demographic information (Hodge, 2007). Therefore, Facebook Inc. has access to the exact population parameters of Facebook users and can precisely monitor patterns in user behavior, which it discloses at its discretion. Some basic statistics reported by Facebook Inc. include the findings that the average user has 130 friends, contributes 90 pieces of content per month, and is connected on average with 80 community pages, groups, and events (Facebook, 2012). The information revealed by Facebook Inc. is helpful but meager — all the available demographic and usage information is presented on a one-page document posted on Facebook's website (see Facebook, 2012).

In addition to this one-page document, Facebook Inc. also has a team of in-house researchers (e.g., Lars Backstrom, Moira Burke, Jonathan Chang, Adam Kramer, Thomas Lento, Cameron Marlow, Itamar Rosenn, Eric Sun; See Facebook, 2011a) who have access to the anonymized web logs of the full Facebook dataset, and consequently have produced some of the most informative studies regarding demographics and behavior on Facebook. For instance, in collaboration with researchers at the Università degli Studi di Milano, the Facebook research team produced two studies that examined 721 million Facebook users with a combined 69 billion friendships (Backstrom, Boldi, Rosa, Ugander, \& Vigna, 2011; Ugander, Karrer, Backstrom, \& Marlow, 2011). To date, these are the largest social network studies ever released (Backstrom, 2011), and it is likely that these sample sizes are the largest in history. Some major findings 
included: (1) $92 \%$ of users were connected by only four degrees of separation, meaning any two people were on average separated by no more than four intermediate connections; further, the degrees of freedom separating users is shrinking as Facebook grows; (2) after measuring how many friends people had, researchers found a curvilinear, highly skewed distribution such that $20 \%$ of users had less than 25 friends, $50 \%$ of users had over 100 friends, and a small percentage of people had close to 5,000 friends, which is the maximum number of friends allowed by Facebook; (3) users' friends were most likely to be of a similar age and from the same country; (4) the average number of Facebook friends in the U.S. was 214 (Backstrom, 2011; Backstrom et al., 2011; Ugander et al., 2011), somewhat higher than the Worldwide average of 130 reported by Facebook (2012). Researchers who do not work or collaborate with Facebook Inc. have devised alternate methods for data collection: Recruitment of participants in offline contexts, recruitment of participants via Facebook applications, and data crawling (see Appendix C for a description of each).

Ninety-seven (24\%) of the 410 articles in the review focused on descriptive analysis of Facebook, providing baseline information on demographic patterns and time-use trends that can inform future studies of Facebook activity. The articles in this section tended to be descriptive, with an emphasis on exploring who is on Facebook (e.g., by comparing users with non-users) and on how sub-populations within Facebook (e.g., based on race, sex, age, country, membership in user groups) behave differently. For example, one research team analyzed 77,954 U.S. Facebook profiles and found that the breakdown of ethnicities on Facebook has grown more diverse over time and currently mirrors the proportions represented in the U.S. population (Chang, Rosenn, Backstrom, \& Marlow, 2010). To better understand the global distribution of Facebook users, another study found that the top five countries with users on Facebook were the 
U.S. (155 million users), Indonesia (36.6), the U.K. (29.8), Turkey (28.4), and India (25.5;

Carmichael, 2011; for a breakdown of users by continent, see

http://www.internetworldstats.com/facebook.htm).

Potential for research comparing demographic groups. As the above studies show, the broad composition of Facebook users provides an exceptionally useful opportunity to examine trends both within and across countries in an ecologically compelling manner. Our review revealed that many articles explored trends within countries, but even basic direct comparisons of samples across countries were rare. The lack of cross-cultural research is unfortunate because behavioral data gathered from Facebook is well-suited to explore cultural differences. Past research has demonstrated that self-reports can be poor indicators of how people vary across cultures because social norms may shape responses, leading to a shifting baseline of comparison (Heine, Lehman, Peng, \& Greenholtz, 2002; Hong, Morris, Chiu, \& Benet-Martinez, 2000; Ramírez-Esparza, Gosling, \& Pennebaker, 2008). For example, one study (unrelated to Facebook) found that Mexican participants rated themselves as less sociable than American participants on self-reports but an independent analysis of behavior showed that the Mexican participants actually behaved more socially in their everyday lives (Ramírez-Esparza, Mehl, Álvarez-Bermúdez, \& Pennebaker, 2009. This discrepancy illustrates the problems of cultural framing and shifting norms associated with comparing self-reports across cultures, and cultural psychologists have strongly recommended using behavior as a comparative metric; Facebook provides a convenient context to assess a wide range of socially important behaviors across cultures.

In addition to exploring differences between countries, future research should continue to compare trends across demographic groups. Such findings would provide valuable contextual 
information about Facebook users in general and may also help explain some specific research findings. For example, it is reasonable to suppose that many of the basic Facebook findings now reported could differ across high-school students, college students, middle-age users, and older users. Such possibilities are quite plausible given studies showing substantially different usage patterns across age groups. For example, a study by researchers at Microsoft found that employees' Facebook use was inversely correlated with age (Archambault \& Grudin, 2012). Other research has found that younger users (15-30 year olds) had eleven times more friends than older users (50+ year olds; Quinn, Chen, \& Mulvenna, 2011). Such evidence indicates that as Facebook continues to grow internationally and infiltrate broader demographic groups, exploring basic differences in how these groups use Facebook will become increasingly important.

The rapid growth of Facebook, along with network expansions (as documented in Figure 1) and changes to the layout of the Facebook site, highlight an important issue when interpreting Facebook studies. Readers and researchers must take into account that there were over 140 times more users in 2011than in 2005 and many features of the site have been added over this period (see Figure 1). So comparing studies from 2005 with those from 2011 is potentially misleading.

However, there are a few reasons to suppose that findings from Facebook studies do not become obsolete every time Facebook changes its features or as new kinds of users sign up. First, the site's network organizational structure, in which users are grouped in networks of friends, buffers the users from most changes to the overall demographics of the broader Facebook population. For example, a college student Facebook user in Oklahoma will be largely unaffected by user growth in Indonesia because Indonesians are unlikely to be added into his network. To help readers understand the reach of reported findings, we urge researchers to pay 
close attention to and report demographic variables as they interpret their data.

Second, while Facebook Inc. is constantly updating the features of the site, the changes are largely additive, with drastic changes becoming less common as the site matures. The core Facebook experience has remained largely unchanged from the beginning, always focusing on the users' ability to: (a) post self-relevant information on an individualized profile page; (b) link to other members and create a 'friends' list, and (c) interact with other members (Buffardi \& Cambell, 2008; Tufekci, 2008).

Finally, studying Facebook is conceptually similar to studying any culture over time, where fluidity is to be expected and measured, not interpreted as a fatal design flaw (Lopez \& Guarnaccia, 2000). As with culture, an expectation that Facebook should consist of static demographic patterns and unchanging social processes would neglect the element of change that is a core feature of the OSN. Culture shifts with time. Populations grow, laws are amended, and people's perceptions living in a culture change. Such change is also inherent in Facebook use, and it is incumbent on researchers in the social sciences to account for these changes and recognize both the importance of measured change and the limitations intrinsic to the study of Facebook over time.

\section{Why Do People Use Facebook?}

Seventy-nine (19\%) articles examined what motivates people to use Facebook. Articles on user motivation varied in their focus and methodology, but in general these studies can be split into one of two subcategories regarding the researchers' perspectives on the motivations underlying Facebook use. One subcategory emphasized the external press that encouraged users to engage in Facebook-related behaviors, such as the features on the site like the birthday reminder or automatic emails sent by Facebook to users (Viswanath et al., 2009). However, the 
majority of articles fell into another subcategory, which focused on internal motivations for Facebook use, such as the need for social engagement. Of course, these two subcategories represent two sides of the same coin because motivations are both prompted by the pressures and opportunities afforded by the external world and driven by internal motives (Murray, 1938).

The most common internal motivation discussed in the literature was users' desire to keep in touch with friends (Ellison, Steinfield, \& Lampe, 2006; Joinson, 2008; Lampe, Ellison, \& Steinfield, 2006; Saleh, Jani, Marzouqi, Khajeh, \& Rajan, 2011; Sheldon, 2008). Expanding on these findings, researchers have explored the underlying influence of "social capital," which refers to the benefits received from relationships with other people (Steinfield, Ellison, \& Lampe, 2008). To understand the connections between social capital and Facebook relationships, researchers have distinguished between strong and weak ties among Facebook friends (Granovetter, 1973). A typical Facebook user will directly communicate with a small core group of friends by posting comments or messages, indicating strong ties, and then follow the majority of friends through passive means such as viewing the News Feed and browsing, indicating weak ties (Burke, Marlow, \& Lento, 2010). Research has shown that users are able to cultivate weak ties in an informal manner, and Facebook use may help maintain previous relationships and crystallize otherwise ephemeral relationships (Ellison, Steinfield, \& Lampe, 2007; Lewis \& West, 2009).

In addition to increasing social capital, Facebook use may help fulfill social-grooming needs (Dunbar, 1998; Gosling, 2009). In many non-human primate species, physical grooming plays a significant role in maintaining social bonds and promoting group stability (Dunbar, 1998). In humans, Dunbar has suggested that seemingly superfluous acts like gossip and small talk serve a similar social grooming role. Certainly, users of online networking sites engage in 
activities that can be conceptualized as social grooming (Tufekci, 2008). Consequently, Gosling (2009) speculated that Facebook's popularity may be due, in part, to the ease with which it allows individuals to satisfy a similar basic desire to monitor other network members and maintain social bonds, even in networks that are geographically dispersed. Facebook provides an excellent medium for studying the processes that comprise social grooming because actions that cannot be easily captured in face-to-face interactions (e.g., commenting on another's appearance) often leave a measurable trace in Facebook interactions.

Minimizing loneliness may motivate some Facebook activity, but the research reviewed here suggests that the association between Facebook use and loneliness is complex. A 2010 survey of 1,193 participants found correlational evidence that users who engaged in directed interaction with others, such as leaving wall posts or messaging friends, reported lowered feelings of loneliness and increased feelings of social capital (Burke, Marlow, \& Lento, 2010). However, users who predominantly spent time on Facebook passively viewing friends' content, such as status updates and photos, without actively engaging in interaction reported feelings of increased loneliness and reduced social capital (Burke et al., 2010). Complimenting these findings, a separate study measured the physiological indicators of emotion by observing participants who browsed Facebook in an undirected manner for five minutes while in a lab setting. The researchers found that users who engaged in extractive social searching (e.g., directed clicking on a friends' profiles) showed greater physiological evidence of pleasure than users who browsed passively (e.g., undirected viewing of the newsfeed; Wise, Alhabash, \& Park, 2010). Together, these studies demonstrate that a complex relationship exists between differing types of user engagement and the consequent benefits gained from Facebook use. Future studies are needed to map the intricacies of this relationship and to unpack the psychological processes 
that drive them.

A more mundane internal motivation for engaging in Facebook activities may be to relieve boredom (Lampe, Ellison, \& Steinfield, 2008). Participants have reported using Facebook simply to pass time, and boredom was stated as a reason for Facebook use (Lampe et al., 2008). However, students used Facebook regardless of how busy they were, suggesting that boredom is unlikely to be the only factor influencing Facebook use (Pempek, Yermolayeva, \& Calvert, 2009).

In the domain of Facebook activities, research has investigated the motives for engaging in specific behaviors, such as adding content or joining groups. For example, one study investigating content contributions found that $54 \%$ of interactions between pairs of users who interact infrequently were directly attributable to Facebook's birthday reminder feature (Viswanath, Mislove, Cha, \& Gummadi, 2009). This finding points to the importance of features built into the Facebook site in motivating user interaction. The success of Facebook makes it clear that powerful motivations are driving people to join and use this OSN. It is equally clear that researchers do not know exactly why Facebook has become so popular, and research that builds on the current findings about motivation promises to be an important area for future investigations.

\section{How Are People Presenting Themselves on Facebook?}

Fifty $(12 \%)$ of the articles in our review investigated identity presentation, which can be defined as the process by which individuals share part of the self with others (Altheide, 2000; see Friedlander, 2011 for a review of the history of identity presentation prior to Facebook). Identity presentation on Facebook centers on the user profile, which serves as a stage upon which users can make public or semi-public presentations of themselves. New users are presented with blank 
profiles, which they personalize by entering information about themselves into a series of standard fields. Of course, Facebook profiles are not created in a social vacuum, and interactions with other users plays an important role in shaping identity presentation. Studying how users choose to portray themselves in their profile presents an excellent opportunity for social scientists to study identity presentation in a naturalistic, socially consequential setting.

Unlike other kinds of online profiles (e.g., dating profiles), Facebook profiles afford opportunities for others to contribute content (e.g., via wall posts, comments, and photo tags). However, most of the information on a profile is furnished by the user, providing opportunities for users to present themselves authentically, or to cast themselves in a positive (or negative) light, or even to fabricate some other image. The potential for profile authors to manipulate their profile raises a critical question: Do Facebook profiles convey accurate impressions of the profile owners? A number of papers have attempted to answer this question. In one study of 133 Facebook users, researchers tested whether profiles represented idealized virtual identities or accurate portrayals of the users' personalities (Gosling, Gaddis, \& Vazire, 2007). A more robust set of analyses combined this Facebook dataset with an equivalent dataset from the German OSN StudiVZ (Back et al., 2010). In both datasets, strangers' ratings of participants based solely on the participants' user profiles were compared with an accuracy criterion (consisting of the participants' self-ratings and ratings of the participant by multiple informants who knew the participants offline) and with participants' ideal-self ratings. The findings, which did not differ across samples, showed that observer ratings correlated strongly with the criterion measure but weakly with the ideal-self ratings, suggesting that OSN profiles convey fairly accurate personality impressions of profile owners (Back et al., 2010). Other research has supported this finding, concluding that although some self-enhancement may occur, profile owners are 
generally portraying a fairly accurate representation of their offline identity (Waggoner, Smith, \& Collins, 2009; Weisbuch, Icevic, \& Ambady, 2009).

The veracity of information given by profile owners on Facebook might be explained, in part, by the prevalent sequence of friendship formation, in which individuals typically become online Facebook friends after being offline friends. Unlike many other social networking sites (e.g., Badoo, Habbo), offline relationships tend to lead to Facebook relationships, rather than the other way around (Lampe et al., 2006; Ross et al., 2009). Therefore, if an owner presented inaccurate or enhanced information on their Facebook profile, their online friends, who also know the user from offline contexts, would realize that the user was not telling the truth (Pempek et al., 2009). As a consequence of this offline-to-online sequence, statements about interests and values are likely to be authentic (Lampe et al., 2006; Lampe, Ellison, \& Steinfield, 2007; Pempek et al., 2009; Ross et al., 2009).

Another reason why Facebook profiles elicit accurate impressions may be that individuals generally want others to see them as they see themselves. Research on selfverification theory suggests that people are not as motivated to self-enhance when they are certain about the strength of a relationship or when the relevant self-views are firmly held (Swann, 1999). Therefore, one might expect more self-enhancement when people are new to Facebook or uncertain about the specific bonds they have with their Facebook friends.

Despite the obstacles to portraying oneself in an overly positive light, it is possible that some positive spin occurs on Facebook profiles. In what circumstances might profile information be enhanced or inaccurate, and why? Narcissists are one group that engages in self-promotion on their Facebook profiles (Buffardi \& Cambell, 2008). However, although narcissists presented an idealized online profile, independent raters saw through the deception and accurately judged the 
profile authors as narcissistic (Buffardi \& Cambell, 2008). One study found that introverted users with low self-esteem and low offline popularity admitted to doing things on Facebook to make themselves look more popular, such as editing their profile in certain ways or un-tagging unflattering photos; however there was no evidence that the self-promotion strategies were effective (Zywica \& Danowski, 2008).

Assumptions about the perceived audience as well as cultural norms may also influence how users portray themselves on Facebook. One study showed that students in the United States were more inclined to post inappropriate content than German students on Facebook (Karl et al, 2010b), which parallels previous research on differing conventions between the two countries (Hofstede, 1991) and points to the influence of cultural norms on Facebook identity construction. The study highlights the potential role of cultural influences and perceived audience on selfpresentation strategies, mirroring the concerns that affect self-presentation strategies in offline contexts (Goffman, 1959).

Most information about identity is furnished by the profile owner, but observers' impressions of Facebook users are also affected by the user's number of friends and the characteristics of friends, especially those who write on the wall of the user (Walther, Van Der Heide, Hamel, \& Shulman, 2009). A curvilinear relationship exists between a user's number of friends and observers' ratings of the user's attractiveness and extraversion; one study showed that the correlation remains positive up until about 300 friends and then declines, perhaps because an overabundance of friends created less credibility (Tong, Van Der Heide, Langwell, \& Walther, 2008). Other research showed that the attractiveness of the people leaving posts on a user's wall affected impressions of the user; users with walls where the posts were left by attractive people were judged to be more attractive than those very same users when the same 
posts were left by unattractive users (Walther et al., 2008). Perhaps because of this phenomenon, both males and females are more willing to become friends with users that have attractive (vs. unattractive) photos (Wang, Moon, Kwon, Evans, \& Stefanone, 2010) and less likely to hide attractive (vs. unattractive) friends, even when they posted negative messages (Peña, \& Brody, 2011). Taken together, these studies demonstrate that friend characteristics provide indirect yet meaningful contributions to perceived profile identity (Tong et al., 2008).

\section{How is Facebook Affecting Relationships Among Groups and Individuals?}

Research on social interactions was studied frequently, in $111(27 \%)$ articles. These articles examined the positive and negative effects of Facebook on relationships between groups and among individuals (e.g., students/faculty, employees/management, businesses/customers, doctors/patients, romantic partners). In addition, articles in this category discussed how the benefits of strengthened relationships on Facebook may be tempered by tensions that arise as a result of overlapping social spheres, such as those between work and non-work contexts (Binder, Howes, \& Sutcliffe, 2009).

Relationships between groups of users on Facebook. Some researchers have looked at how Facebook is changing relationships between companies and customers (e.g., Cvijikj, Spiegler, \& Michahelles, 2011). To gauge the usefulness of Facebook as a business tool, one team of researchers conducted a case study of a bakery in Houston to examine the usefulness of Facebook as a marketing and customer-service tool (Dholakia \& Durham, 2010). A survey of 689 customers provided baseline opinions towards the bakery and participants were subsequently invited to join the bakery's Facebook fan page. Participants reported an increase in store visits per month after joining the fan page, suggesting that Facebook can act as an effective niche marketing tool. In addition to increasing interaction with customers, company pages also give 
businesses a continuous source of consumer feedback, which can act as an important source of information when it comes to adapting and improving products (Pantano, Tavernise, \& Viassone, 2010). Of course, these few studies only begin to touch on ways in which Facebook can be used to connect with customers. A few articles attempted to assess the ultimate financial value of using Facebook as a business tool (e.g., Syncapse, 2010), but much research in this area remains to be done.

As business and marketing researchers strive to help companies engage with customers through Facebook, other research offers a more cautious outlook on the benefits of Facebook contact. For example, a large number of articles examined the role of Facebook on student/faculty relationships. Interestingly, the studies focus largely on students' perceptions of faculty, not faculty perceptions of students. One study found that students predicted a positive classroom environment and high motivation when a teacher shared more personal information on their Facebook profile page (Mazer, Murphy, \& Simonds, 2009). Other research warned of the dangers that arise when a teacher becomes friends with students on Facebook, including being charged with sexual harassment, breaking political correctness, and being seen as "creepy" (Lipka, 2007; Madge, Meek, Wellens, \& Hooley, 2009). However, a study in this area found that only $4 \%$ of users' wall postings refer to education and the vast majority of students report not contacting university staff on Facebook for any reason, suggesting that concern over the appropriateness of student/faculty Facebook interaction may be unfounded because these interactions are not prevalent (Madge et al., 2009; Selwyn, 2009). Readers interested in learning more about students' and teachers' Facebook use are referred to Hew's (2011) thorough review of the topic.

Similarly, the benefits accruing from Facebook interactions between businesses and 
employees may be mixed (Stopfer \& Gosling, in press). Specifically, employers have begun using Facebook to evaluate job candidates in hiring decisions (Karl, Peluchette, \& Schlaegel, 2010b; Kluemper \& Rosen, 2009). Given the findings reported in the identity presentation section of this paper, which suggest that impressions based on Facebook profiles are generally accurate, it may make good sense from the employer's perspective to evaluate the information found on Facebook profiles (Back et al. 2010; Waggoner et al., 2009; Weisbuch et al., 2009). However, by using Facebook to screen applicants, employers can inadvertently learn about a candidate's marital status, age, and other topics that are not legal bases for hiring decisions according to equal opportunity laws in the U.S. (Kluemper \& Rosen, 2009). As a result of these concerns, researchers have warned that employers may be open to discrimination lawsuits (Kluemper \& Rosen, 2009).

As might be expected, information presented on Facebook can both help and hurt job candidates. One study showed that, if a job candidate's Facebook profile emphasized family values or professionalism, the chances of the applicant being offered a job increased (Bohnert \& Ross, 2010). Conversely, if a profile contained inappropriate material, such as alcohol and drugs, then a candidate's prospects decreased (Bohnert \& Ross, 2010). Some applicants are judged with disproportionate harshness when they post inappropriate material. For example, female job candidates suffered more than their male counterparts when their Facebook profiles were judged by potential employers (Karl \& Peluchette, 2008). Such unequal judgment highlights the dangers that exist when users decide to post improper content on their profiles as well as the potential for discrimination when using Facebook as a hiring tool (see Brown \& Vaughn, 2011 for further review of this topic).

Tension across social spheres. The above findings raise the basic question of why any 
user would post inappropriate information on their Facebook profile. Users' 'friends' on Facebook often include overlapping social groups (e.g., family, friends, employers) and this overlap could create tension (Binder et al., 2009). These different spheres are traditionally partitioned into different contexts, but on Facebook they are sometimes combined into a single context. A user whose Facebook friends encompass family members, employers, and college friends may have difficulty presenting information that is appropriate across all social spheres simultaneously (Lampinen, Tamminen, \& Oulasvirta, 2009). For example, a photo of the user drinking heavily may be acceptable in the context of college friends but not in the context of work or family.

Despite these potential concerns, one study found that the co-presence of multiple groups did not cause tension for users (Lampinen et al., 2009). Users seemed to mitigate any uncomfortable overlap among their social spheres by implementing a number of strategies including the use of detailed privacy controls to limit the access of certain friends, choosing more private communication channels for certain information (e.g., messaging rather than posting on others' walls), and self-censoring potentially problematic content (Lampinen et al., 2009). The overlap of social spheres on OSNs presents a new domain in which to study self-verification processes and, more broadly, how individuals negotiate the task of selective self-presentation.

\section{Why Are People Disclosing Personal Information on Facebook Despite Potential Risks?}

Research on privacy and personal information disclosure was the focus of 73 articles $(18 \%)$ in our review. These articles discussed the risks associated with revealing information on Facebook and assessed the motivations that impelled users to share personal information despite these risks. (For readers wanting greater context, a brief history of recent Facebook privacy policy shifts is provided in Appendix D.) 
The information disclosure-privacy dilemma. As with any social networking site, Facebook is only as good as the content that users share. Therefore a design that encourages content contribution improves the overall user experience (Burke et al., 2009). But the sharing of content and personal information on Facebook comes with certain potential privacy risks, including unintentional disclosure of personal information, damaged reputation due to rumors and gossip, unwanted contact and harassment, vulnerability to stalkers or pedophiles, use of private data by a third party, hacking, and identity theft (boyd, 2008; Debatin, et al., 2009; Taraszow, Arsoy, Shitta, \& Laoris, 2008). The tradeoff between potential benefits and risks that accompany privacy settings presents a dilemma, both for Facebook administrators and Facebook users. Facebook administrators have the incentive to keep security and access controls weak by design in order to encourage information exchange and increase their company's value to advertisers. Yet at the same time the administrators want to avoid a privacy scare similar to the MySpace pedophile panic, a sensationalist scare that drove people away from using MySpace (Raynes-Goldie, 2010). Paradoxically, Facebook has both a comprehensive privacy-protection architecture and significant privacy problems (Anthonysamy, Rashid, \& Greenwood, 2011). In an attempt to explain this incongruity and better understand privacy issues on Facebook, researchers have explored information disclosure and attitudes towards privacy.

A review of the privacy literature. One of the first comprehensive studies to investigate privacy on Facebook surveyed more than 4,000 Carnegie Mellon University student users and found that participants were willing to provide large amounts of personal data on Facebook (Gross \& Acquisti, 2005). The participants were largely unconcerned about or oblivious to personal privacy risks on Facebook. Over $50 \%$ of participants provided their current address and $40 \%$ of participants provided their phone number but only a handful of individuals changed the 
highly permissive privacy settings (Gross \& Acquisti, 2005). In contrast to these findings, a 2007 study with 205 student participants found that only $10 \%$ of participants provided their home address (Fogel \& Nehmad, 2009). Additionally, a 2008 study with 1,740 students found that an entire third of student participants had changed their privacy default setting to a more restrictive setting, suggesting that awareness of privacy and security issues had increased (Dey, Jelveh, \& Ross, 2012; Lewis, Kaufman, Gonzalez, Wimmer, \& Christakis, 2008a).

Supporting the premise that users' attitudes shifted towards greater privacy concern over time, a 2009 study confirmed that participants were generally concerned with personal privacy on Facebook (Christofides, Muise, \& Desmarias, 2009). Such a shift may be partly explained by increased threats to unwanted information disclosure, such as data crawling by third parties. However, research has revealed a disparity between reported privacy concerns and observed privacy behaviors (Acquisti \& Gross, 2006; Stutzman \& Kramer-Duffield, 2010; Tufekci, 2008). For instance, $16 \%$ of respondents who reported being "very worried" about the possibility that a stranger knew where they lived and the location of their classes still revealed both pieces of information on their Facebook profile (Acquisti \& Gross, 2006). Attempting to understand this discrepancy, a study found that privacy concerns were primarily determined by the perceived likelihood of a privacy violation and much less by the expected damage (Krasnova, Kolesnikova, \& Gunther, 2009); specifically, the perceived likelihood of a privacy violation had a medium effect on privacy concerns but perceived damage had a negligible effect on privacy concern (Krasnova et al., 2009). Additional research has revealed another potential reason for the inconsistency between reported concerns and behavior-privacy concerns and disclosure were not negatively correlated, suggesting that they may not be two ends of the same spectrum, but independent behaviors influenced by different aspects of personality (Christofides et al., 2009; 
McKnight, Lankton, Tripp, 2011).

One study from the 'Motivations' literature provides a perspective that might help explain potential influences on information disclosure other than privacy concerns. To test the extent to which social learning motivates content sharing by new members, researchers analyzed data from 140,292 Facebook profiles, using information from their first 3 months of Facebook membership (Burke, Marlow, \& Lento, 2009). Findings revealed that new members were closely monitoring and adapting to what their friends were doing, and that the experiences in the first two weeks predicted long-term sharing. For example, relatively inactive newcomers are more likely to upload photos to their profile if they observe a comment about a friend's photo uploads (Burke et al., 2009). This research demonstrated that social learning and social comparison are important influences on new users, and that people closely follow the actions of their friends on Facebook and adapt their content contributions accordingly (Burke et al., 2009). (This study also illustrates how some studies in our review were relevant to multiple categories).

\section{Conclusions and Recommendations}

The studies to date have demonstrated the value of Facebook as a domain in which to conduct social science research. However, the overarching conclusion emanating from the literature as a whole is that much remains to be done. By providing the first comprehensive collection of Facebook research reports (see Appendix B), we hope to help bring some clarity to research in this new domain and provide a foundation on which subsequent research can build. We attempted to identify every published empirical report on Facebook, subject to our review criteria (e.g., reporting data specific to Facebook in cases where multiple OSNs were included). Inevitably, some reports will have slipped through our net, but we believe our search strategy captured the vast majority of relevant sources. Facebook literature continues to be published at 
an escalating rate so to help investigators keep up with the most current Facebook research, we have created a website (www.facebookinthesocialsciences.org) that maintains an updated bibliography of Facebook articles. Researchers interested in a broader bibliography of OSN research are directed to danah boyd's website, http://www.danah.org/researchBibs/sns.php.

To ensure future research is effective in addressing the issues encountered by previous studies, we offer the following recommendations. First, researchers should carefully decide on the method they use to gather data from Facebook. As noted in an earlier section, there are three principle methods to collect Facebook data: Recruitment of participants in offline contexts, recruitment of participants via Facebook applications, and data crawling (see Appendix $\mathrm{C}$ for a more detailed description of the methods). Each method has pros and cons in regards to the quality of data gathered, and the choice of method depends largely on the type of research question that is being asked. In addition, some methods, such as data crawling, are becoming less informative over time as privacy restrictions are strengthened, while other methods (e.g., use of Facebook applications) are continuing to be used successfully. Naturally, researchers must explain to users what information is being collected and how the information will be used and then design protocols that protect the information.

Second, certain disciplines in the social sciences (e.g., developmental psychology, cultural psychology) seem to have underappreciated Facebook as a source of relevant data. The Facebook profile page amounts to a blank canvass upon which each user has free reign to construct a public or semi-public image of him or herself. Studying the process by which this image is created provides a valuable new perspective on identity formation, and examining the interpersonal interactions on Facebook provides an unprecedented opportunity to study a wide variety of social phenomenon in a naturalistic setting. 
In an effort to overcome the problems inherent in comparative studies of OSNs, we offer the following framework as a way to bring order to this nascent research domain. In our literature review of Facebook, we identified five broad categories of research that correspond to five broad questions: (1) Who is using Facebook and what are users doing while on Facebook? (2) Why do people use Facebook? (3) How are people presenting themselves on Facebook? (4) How is Facebook affecting the relationships among groups and individuals? And (5) why are people disclosing personal information on Facebook despite potential risks? For the purposes of comparison, we anticipate that it would profitable to conceptualize research on other OSNs in terms of these five key questions. By replacing "Facebook" in the above questions with other OSNs (e.g., MySpace, LinkedIn) researchers can effectively analyze core differences and similarities among OSNs. Such comparative analyses will allow researchers to reach conclusions that are applicable across OSNs while recognizing the attributes that are unique to each. If indepth reviews of specific OSNs (such as the present report) are conducted on other OSNs, then together these findings can be combined with broader surveys of OSNs in general (e.g., boyd \& Ellison, 2007) and with domain-specific comparisons of OSN usage (e.g., Stopfer \& Gosling, in press).

As Facebook and other OSNs continue to grow in worldwide influence and online ubiquity, people are now engaging with the Internet in a more socially interactive manner. These developments represent a fundamental shift in the role of the Internet in daily life, and researchers are only beginning to understand the impact of these changes. A dramatic example of the emerging importance of OSNs in shaping modern society was displayed in the 2011 Egyptian overthrow of longtime president Hosni Mubarak. With over five million users in Egypt, Facebook seemed to play a particularly pivotal role as protesters used the site to organize and 
energize the grassroots uprising. The protests began on January 25, 2011, and during the following two weeks over 32,000 new groups and 14,000 new pages were created on Facebook in Egypt (“Egyptian Couple,” 2011).

After Mubarak relented to public pressure and resigned as president, an Egyptian couple named their newborn girl Facebook Jamal Ibrahim in an expression of gratitude to honor the role Facebook played in the historic event ("Egyptian Couple," 2011). Such a striking incident underscores the importance of Facebook and other OSNs in modern society. Social scientists must continue to conduct research in order to better understand this growing new domain, and we hope that our efforts at drawing together the pioneering studies on Facebook will provide a foundation on which subsequent research can be built.

\section{Acknowledgment}

We thank Juliane Stopfer and Simine Vazire for feedback on an earlier version of this article.

\section{Article Notes}

The authors declared that they had no conflicts of interest with respect to their authorship or the publication of this article. 


\section{References}

Acquisti, A., \& Gross, R. (2006). Imagined communities: Awareness, information sharing and privacy on The Facebook. Proceedings of the 6th Workshop on Privacy Enhancing Technologies, Cambridge, UK.

Altheide, D.L. (2000). Identity and the definition of the situation in a mass-mediated context. Symbolic Interaction, 23, 1-27.

Anthonysamy, P., Rashid, A., \& Greenwood, P. (2011). Do the privacy policies reflect the privacy controls on social networks? 2011 IEEE Third International Conference on Privacy, Security, Risk and Trust,, 1158.

Archambault, A., \& Grudin, J. (2012). A longitudinal study of Facebook, LinkedIn, \& Twitter use. in press. Proceedings CHI 2012.

Arrington, M. (2005). 85\% of college students use Facebook. TechCrunch, Retrieved October 13, 2005 from www.techcrunch.com/2005/09/07/85-of-college-students-use-facebook.

Back, M.D., Stopfer, J.M., Vazire, S., Gaddis, S., Schmukle, S.C., Egloff, B., \& Gosling, S.D. (2010). Facebook profiles reflect actual personality, not self-idealization. Psychological Science, 21, 372-374.

Backstrom, L. (2011). Anatomy of Facebook. Palo Alto, CA: Facebook. Retrieved February 14, 2012 from http://www.facebook.com/note.php?note_id=10150388519243859

Backstrom, L., Boldi, P., Rosa, M., Ugander, J., \& Vigna, S. (2011). Four degrees of separation. Retrieved February 14, 2012 at http://arxiv.org/abs/1111.4570

Barker, V. (2009). Older adolescents' motivations for social network site use: The influence of gender, group identity, and collective self-esteem. CyberPsychology \& Behavior, 12, 209213. 
Baumeister, R. F., Vohs, K. D., \& Funder, D. C. (2007). Psychology as the science of selfreports and finger movements: Or, whatever happened to actual behavior? Perspectives on Psychological Science, 2, 396-403.

Bilton, N. (2010, May 13). Price of Facebook privacy? Start clicking. New York Times, B8.

Binder, J., Howes, A., \& Sutcliffe, A. (2009). The problem of conflicting social spheres: effects of network structure on experienced tension in social network sites. $27^{\text {th }}$ International conference on Human factors in computing system, Boston, MA, USA.

Bohert, D., \& Ross, W.H. (2010). The influence of social networking web sites on the evaluation of job candidates. Cybertechnology, Behavior, and Social Networking, 13, 1-7.

boyd, d., \& Ellison, N. (2007). Social network sites: Definition, history, and scholarship. Journal of Computer-Mediated Communication, 13, Article 11.

boyd, d. (2008). Facebook's privacy trainwreck: Exposure, invasion, and social convergence. The International Journal of Research into New Media Technologies, 14, 13-20.

Braun, V., \& Clarke, V. (2006). Using thematic analysis in psychology. Qualitative Research in Psychology, 3, 77-101.

Brown, J. (2008). From Friday to Sunday: the hacker ethic and shifting notions of labour, leisure and intellectual property. Leisure Studies, 27, 395-409.

Brown, V. R., \& Vaughn, E. (2011). The writing on the (Facebook) wall: The use of social networking sites in hiring decisions. Journal of Business and Psychology, 26, 219-225.

Buchanan, E., \& Ess, C. (2011, March 4). Internet Research Ethics. Website retrieved on March 4, 2011 from http://internetresearchethics.org/

Buffardi, L. E. \& Campbell, W. K. (2008). Narcissism and social networking web sites. Personality and Social Psychology Bulletin, 34, 1303-1314. 
Burke, M., Marlow, C., \& Lento, T. (2009). Feed me: Motivating newcomer contribution in social network sites. Proceedings of the 27th international conference on Human factors in computing systems, 945-95.

Burke, M., Marlow, C., \& Lento, T. (2010). Social network activity and social well-being. Postgrad Med Journal, 85, 455-459.

Carmichael, M. (2011). The demographics of social media. Ad and Marketing News. Website retrieved on June 8, 2011 from http://adage.com/article/adagestat/demographicsfacebook-linkedin-myspace-twitter/227569/

Chang, J., Rosenn, I., Backstrom, L., \& Marlow, C. (2010). ePluribus: Ethnicity on social networks. Proceedings of the Fourth International Conference on Weblogs and Social Media (ICWSM-10), Washington DC, USA.

Christofides, E., Muise, A., \& Desmarais, S. (2009). Information disclosure and control on Facebook: Are they two sides of the same coin or two different processes? Cyberpsychology \& Behavior, 12, 341-345.

Cvijikj, I., Spiegler, E., \& Michahelles, F. (2011). The effect of post type, category and posting day on user interaction level on Facebook. 2011 IEEE Third International Conference on Privacy, Security, Risk and Trust and 2011 IEEE Third International Conference on Social Computing, 810-813.

Debatin, B., Lovejoy, J. P., Horn, A., \& Hughes, B. N. (2009). Facebook and online privacy: Attitudes, behaviors, and unintended consequences. Journal of Computer-Mediated Communication, 15, 83-108.

Dey, R., Jelveh, Z., \& Ross, K (2012). Facebook users have become much more private: A largescale study. 4th IEEE International Workshop on Security and Social Networking 
(SESOC), Lugano, Switzerland.

Dholakia, U. M., \& Durham, E. (2010, March). One café chain's Facebook experiment. Harvard Business Review, 88, 26-26.

Dougherty, H. (2010, March 15). Facebook reaches top U.S. ranking. Experian Hitwise. Retrieved from http://weblogs.hitwise.com/heatherdougherty/2010/03/facebook_ reaches_top_ranking_i.html.

Dunbar, R. (1998). Grooming, gossip, and the evolution of language. Cambridge, MA: Harvard University Press.

Egyptian couple names newly-born daughter 'Facebook.' (2011, February 22). Hindustan Times, Retrieved February 22, 2011 from http://www.hindustantimes.com/Egyptian-couplenames-newly-born-daughter-Facebook/Article1-665347.aspx

Ellison, N., Steinfield, C., \& Lampe, C. (2006). Spatially bounded online social networks and social capital: The role of Facebook. Proceedings of the annual conference of the international communication association, Dresden, Germany.

Ellison, N., Steinfield, C., \& Lampe, C. (2007). The benefits of Facebook 'friends:' Social capital and college students' use of online social network sites. Journal of Computer-Mediated Communication, 12, 1143-1168.

Facebook. (2008). Terms of use. Palo Alto, CA: Facebook. Retrieved April 11, 2008 from http://www.facebook.com/terms.php

Facebook. (2010). Statistics of Facebook. Palo Alto, CA: Facebook. Retrieved June 18, 2010 from http://www.facebook.com/press/info.php?statistics

Facebook. (2011a). Facebook data team: Papers. Palo Alto, CA: Facebook. Retrieved March 1, 2011 from http://www.facebook.com/data\#!/data?sk=app_4949752878 
Facebook. (2011b). Facebook terms. Palo Alto, CA: Facebook. Retrieved March 2, 2011 from http://www.facebook.com/terms.php

Facebook. (2011c). Statistics of Facebook. Palo Alto, CA: Facebook. Retrieved August 1, 2011 from http://www.facebook.com/press/info.php?statistics

Facebook. (2012). Statistics of Facebook. Palo Alto, CA: Facebook. Retrieved February 1, 2012 from http://www.facebook.com/press/info.php?statistics

Facebook Users in the World. (2011). Retrieved February 11, 2012, from http://www.internetworldstats.com/stats25.htm

Fletcher, D. (2010, May 31). Friends without borders. TIME Magazine.

Fogel, J., \& Nehmad, E. (2009). Internet social network communities: Risk taking, trust and privacy concerns. Computers in Human Behavior, 25, 153-160.

Friedlander, L. (2011). Friending the virgin: Some thoughts on the prehistory of Facebook. SAGE Open, 1-14.

Furr, R. M. (2009). Personality psychology as a truly behavioural science. European Journal of Personality, 23, 369-401.

Gertner, J. (2011, August 24). Does America need manufacturing? New York Times Magazine, Retrieved August 24, 2011 from www.nytimes.com/2011/08/28/magazine/does-americaneed-manufacturing.html?pagewanted=1\&_r=2\&hp

Ginger, J. (2008). Dataset documentation. The Facebook Project, Retrieved February 12, 2011 from www.thefacebookproject.com/resource/datasets.html\#top

Gjoka, M., Kurant, M., Butts, C. T., \& Markopoulou, A. (2010). Walking in Facebook: A case study of unbiased sampling of OSNs. Proceedings of INFOCOM, San Diego, CA, USA.

Gjoka, M., Kurant, M., Butts, C., \& Markopoulou, A. (2011) Practical recommendations on 
crawling online social networks. IEEE Journal on Selected Areas in Communications, 29, 1872-1892.

Gjoka, M., Sirivianos, M., Markopoulou, A., \& Yang, X. (2008). Poking Facebook:

Characterization of OSN Applications. Proceedings from the first workshop on Online social networks, Seattle, WA, USA.

Goffman, E. (1959). Presentation of self in everyday life. New York: Double Day.

Gosling, S. (2009, March 20). The ancient psychological roots of Facebook behavior. The Harvard Business Review, Retrieved from http://www.blogs.hbr.org/now-newnext/2009/03/the-ancient-psychological-root.html

Gosling, S. D., Gaddis, S., \& Vazire, S. (2007). Personality impressions based on Facebook profiles. International conference on Weblogs and Social Media, Boulder, CO.

Graham, L. T., \& Sandy, C. J., \& Gosling, S. D. (2011). Manifestations of individual differences in physical and virtual environments. In T. Chamorro-Premuzic, S. von Stumm, \& A. Furnham (Eds.), Handbook of Individual Differences (pp. 773-800). Oxford: WileyBlackwell.

Granovetter, M. (1973). The strength of weak ties. American Journal of Sociology, 78, 13601380.

Grimmelmann, J. (2009). Saving Facebook. Iowa Law Review, 94, 1137-1206.

Gross, R., \& Acquisti, A. (2005). Information revelation and privacy in online social networks. ACM Workshop on Privacy in the Electronic Society, Alexandria, VA, USA.

Heine, S. J., Lehman, D. R., Peng, K., \& Greenholtz, J. (2002). What's wrong with cross-cultural comparisons of subjective Likert scales?: The reference-group effect. Journal of Personality and Social Psychology, 82, 903-918. 
Hew, K. (2011). Students' and teachers' use of Facebook. Computers in Human Behavior, 27, 662-676.

Hodge, M. (2007). The Fourth Amendment and privacy issues on the "new" internet:

Facebook.com and Myspace. Southern Illinois University Law Journal, 31, 95-123.

Hofstede, G. (1991). Cultures and organizations - software of the mind. London, UK: McGrawHill.

Hong, Y. Y., Morris, M. W., Chiu, C. Y., \& Benet-Martínez, V. (2000). Multicultural minds: A dynamic constructivist approach to culture and cognition. American Psychologist, 55, 709-720.

Joinson, A. N. (2008). Looking at, looking up or keeping up with people?: Motives and use of facebook. CHI '08: Proceeding of the twenty-sixth annual SIGCHI conference on Human factors in computing systems, New York, NY, USA, 1027-1036.

Karl, K., \& Peluchette, J. (2008). Facebook follies: Who suffers the most? In C. R. Livermore and K. Setzekorn (eds.) Social Networking Communities and eDating Services: Concepts and Implications, IGI-Global (Information Science Reference), Hershey, PA, USA, 212224.

Karl, K., Peluchette, J., \& Schlaegel, C. (2010a). Who's posting Facebook faux pas? A crosscultural examination of personality differences. International Journal of Selection and Assessment, 18, 174-186.

Karl, K., Peluchette, J., \& Schlaegel, C. (2010b). A cross-cultural examination of student attitudes and gender differences in Facebook profiles. Content. International Journal of Virtual Communities and Social Networking, 2, 11-31.

Kluemper, D. H., \& Rosen, P. A. (2009). Future employment selection methods: evaluating 
social networking web sites. Journal of Managerial Psychology, 24, 567-580.

Krasnova, H., Kolesnikova, E., \& Guenther, O. (2009). "It won't happen to me!": Self-disclosure in online social networks. Proceedings from AMCIS 2009, San Francisco, CA, USA.

Kreutz, C. (2009, June 19). The next billion - The rise of social network sites in developing countries. Web2forDev.com, Retrieved from www.web2fordev.net/component/content/article/1-latest-news/69-social-networks

Lampe, C., Ellison, N., \& Steinfield, C. (2006). A Face(book) in the crowd: Social searching vs. social browsing. Paper presented at the ACM Special Interest Group on ComputerSupported Cooperative Work, Banff, Canada.

Lampe, C., Ellison, N., \& Steinfield, C. (2007). A familiar Face(book): Profile elements as signals in an online social network. CHI 2007 Proceedings, San Jose, CA.

Lampe, C., Ellison, N., \& Steinfield, C. (2008). Changes in use and perception of Facebook. Proceedings of the 2008 ACM conference on Computer supported cooperative work, San Diego, CA, USA.

Lampinen, A., Tamminen, S., \& Oulasvirta, A. (2009). “All my people right here, right now": management of group co-presence on a social networking site. Proceedings of the ACM 2009 international conference on Supporting group work (GROUP '09), ACM, New York, NY, USA, 281-290.

Lewis, J., \& West, A. (2009). 'Friending': London-based undergraduates' experience of Facebook. New Media \& Society, 11, 1209-1229.

Lewis, K., Kaufman, J., Gonzalez, M., Wimmer, A., \& Christakis, N. (2008a). Taste, ties, and time: A new dataset using Facebook.com. Social Networks, 30, 330-342.

Lewis, K., Kaufman, J., \& Christakis, N. (2008b). The taste for privacy: An analysis of college 
student privacy settings in an online social network. Journal of Computer-Mediated Communication, 14, 79-100.

Lipka, S. (2007, December 7). For professors, 'Friending' can be fraught. The Chronicle for Higher Education, 54(15), A1.

Lopez, S.R., \& Guarnaccia, P.J. (2000). Cultural psychopathology: Uncovering the social world of mental illness. Annual Review of Psychology, 51, 571-598.

Madge, C., Meek, J., Wellens, J., \& Hooley, T. (2009). Facebook, social integration and informal learning at university: 'It is more for talking to friends about work than for actually doing work'. Learning, Media and Technology, 34, 141-155.

Markoff, J. (2007, August 31). The tangled history of Facebook. New York Times, Retrieved at http://www.nytimes.com/2007/08/31/business/worldbusiness/31iht facebook.5.7340806.html

Mazur, E. (2010). Collecting data from social networking web sites and blogs. In S. D. Gosling, \& J. A. Johnson, (Eds.), Advanced Methods for Behavioral Research on the Internet. (pp. 77-90) Washington, DC: American Psychological Association.

Mazer, J. P., Murphy, R. E., \& Simonds, C. J. (2009). The effects of teacher self-disclosure via Facebook on teacher credibility. Learning, Media and Technology, 34, 175-183.

McKnight, D., Lankton, N., \& Tripp, J. (2011). Social networking information disclosure and continuance intention: A disconnect. 2011 44th Hawaii International Conference on System Sciences, 1-10.

Murray, H. A. (1938). Explorations in personality. New York, NY: Oxford University Press. Nazir, A., Raza, S., \& Chuah, C. (2008). Unveiling Facebook: A measurement study of social network based applications. Proceedings of the 8th ACM SIGCOMM conference on 
Internet measurement, Vouliagmeni, Greece.

Nazir, A., Raza, S., Gupta, D., Chuah, C., \& Krishnamurthy, B. (2009). Network level footprints of facebook applications. Proceedings of the 9th ACM SIGCOMM conference on Internet measurement conference (IMC '09), ACM, New York, NY, USA, 63-75.

Pantano, E., Tavernise, A., \& Viassone, M. (2010). Consumer perception of computer-mediated communication in a social network. 4th International Conference on New Trends in Information Science and Service Science. Gyeongju, South Korea.

Pempek, T., Yermolayeva, Y., \& Calvert, S. (2009). College students' social networking experiences on Facebook. Journal of Applied Developmental Psychology, 30, 227-238.

Peña, J., \& Brody, N. (2011, May). To unfriend or to block?: Avoiding and terminating Facebook connections based on perceptions of social and physical attractiveness, message face-threatening qualities, and linguistic style. Paper presented at the 61th annual conference of the International Communication Association, Boston, MA, USA.

Quinn, D., Chen, L., \& Mulvenna, M. (2011). Does age make a difference in the behaviour of online social network users?. 2011 International Conference on Internet of Things and 4th International Conference on Cyber, Physical, and Social Computing, 266-272.

Ramírez-Esparza, N., Gosling, S. D., \& Pennebaker, J. W. (2008). Paradox lost: Unraveling the puzzle of Simpatía. Journal of Cross-Cultural Psychology, 39, 703-715.

Ramirez-Esparza, N., Mehl, M. R., Alvarez Bermudez, J., \& Pennebaker, J. W. (2009). Are Mexicans more or less sociable than Americans? Insights from a naturalistic observation study. Journal of Research in Personality, 43, 1-7.

Raynes-Goldie, K. (2010). Aliases, creeping, and wall cleaning: understanding privacy in the age of facebook. First Monday, 15.

Richmond, R. (2010, May 27). A guide to Facebook's new privacy settings. New York Times, 
Retrieved from http://gadgetwise.blogs.nytimes.com/2010/05/27/5-steps-to-reset-yourfacebook-privacy-settings/

Ross, C., Orr, E.S., Sisic, M., Arseneault, J.M., Simmering, M.G., \& Orr, R.R. (2009).

Personality and motivations associated with Facebook use. Computers in Human Behavior, 25, 578-586.

Rusli, E. (2012, February 1). Facebook files for an I.P.O. The New York Times, Retrieved February 1, 2012 from http://dealbook.nytimes.com/2012/02/01/facebook-files-for-an-i$\mathrm{p}-\mathrm{o} / \mathrm{hp}$

Saleh, F., Jani, H., Marzouqi, M., Khajeh, N., \& Rajan, A. (2011). Social networking by the youth in the UAE: A privacy paradox. 2011 International Conference and Workshop on Current Trends in Information Technology, 28-31.

Schonfeld, E. (2010, April 21). Facebook closing in on 500 million visitors a month. TechCrunch, Retrieved June 22, 2010 from http://techcrunch.com/2010/04/21/facebook500-million-visitors-comscore/

Schrag, Z. (2010, November 18). Is Facebook data mining human subjects research? Institutional Review Blog. Retrieved March 3, 2011 from http://www.institutionalreviewblog.com/20 10/11/ is-facebook-data-mining-human-subjects.html

Sheldon, P. (2008). The relationship between unwillingness-to-communicate and students' Facebook use. Journal of Media Psychology: Theories, Methods, and Applications, 20, $67-75$.

Siegler, M. (2011, March 21). Facebook secondary stock just surged to \$34 - That's an \$85 billion valuation. Tech Crunch, Retrieved from http://techcrunch.com/2011/03/21/facebook-85-billion-valuation/ 
Solberg, L. (2010). Data mining on Facebook: A free space for researchers or an IRB nightmare?. University of Illinois Journal of Law, Technology \& Policy, 2, 311.

Steinfield, C., Ellison, N., \& Lampe, C. (2008). Social capital, self-esteem, and use of online social network sites: A longitudinal analysis. Journal of Applied Developmental Psychology, 29, 434-445.

Stillwell, D., \& Kosinski, M. (2011). MyPersonality Project. Retrieved February 23, 2011 from http://www.mypersonality.org/wiki/doku.php

Stopfer, J. M., \& Gosling, S. D. (in press). Online social networks in the work context. In D. Derks \& A. Bakker (Eds.), The Psychology of Digital Media at Work. London: Psychology Press-Routledge.

Stutzman, F., \& Kramer-Duffield, J. (2010). Friends only: Examining a privacy-enhancing behavior in Facebook. CHI 2010 Proceedings, Atlanta, GA, USA.

Swann, W. B., Jr. (1999). Resilient Identities: Self, relationships, and the construction of social reality. Basic books: New York.

Swann, W. B., Jr., Bosson, J. K., \& Pelham, B. W. (2002). Different partners, different selves: Strategic verification of circumscribed identities. Personality and Social Psychology Bulletin, 28, 1215-1228.

Swartz, J. (2012, January 27). Facebook may file for IPO this week. USA Today. Retrieved February 2, 2012 from http://www.usatoday.com/tech/news/story/2012-01-27/facebookipo-could-come-next-week/52823968/1

Syncapse. (2010). The value of a Facebook fan: An empirical review, Research Report, Retrieved February 13, 2012 from http://www.brandchannel.com/images/papers/ 504_061810_wp_syncapse_facebook.pdf 
Taraszow, T., Arsoy, A., Shitta, G., \& Laoris, Y. (2008). How much personal and sensitive information do Cypriot teenagers reveal in Facebook? Proceedings from 7th European Conference on E-Learning, Agia Napa, Cyprus.

Thomas, K., \& Nicol, D. (2010). The Koobface botnet and the rise of social malware. 5th International Conference on Malicious and Unwanted Software (MALWARE), 63-70.

Tong, S., Van Der Heide, B., Langwell, L., \& Walther, J. (2008). Too much of a good thing? The relationship between number of friends and interpersonal impressions on Facebook. Journal of Computer-Mediated Communication, 13, 531-549.

Tsotsis, A. (2011, July 6). Mark Zuckerberg explains his law of social sharing. Tech Crunch. Retrieved October 22, 2011 from http://techcrunch.com/2011/07/06/mark-zuckerbergexplains-his-law-of-social-sharing-video/

Tufekci, Z. (2008). Grooming, gossip, Facebook and Myspace: What can we learn about these sites from those who won't assimilate? Information, Communication \& Society. 11, 544564.

Ugander, J., Karrer, B., Backstrom, L., \& Marlow, C. (2011). The Anatomy of the Facebook Social Graph. Retrieved February 14, 2012 from http://arxiv.org/abs/1111.4503

Vajda, P., Ivanov, I., Goldmann, L., \& Ebrahimi, T. (2011). Social game epitome versus automatic visual analysis. 2011 IEEE International Conference on Multimedia and Expo, $1-6$.

Viswanath, B., Mislove, A., Cha, M., \& Gummadi, K. P. (2009). On the evolution of user interaction in Facebook. Proceedings of the $2^{\text {nd }}$ ACM Workshop on online Social Networks, Barcelona, Spain.

Waggoner, A. S., Smith, E. R., \& Collins, E. C. (2009). Person perception by active verses 
passive perceivers. Journal of Experimental Social Psychology, 45, 1028-1031.

Walther, J., Van Der Heide, B., Kim, S., Westerman, D., \& Tong, S. (2008). The role of friends' appearance and behavior on evaluations of individuals on Facebook: Are we known by the company we keep?. Human Communication Research, 34, 28-49.

Walther, J., Van Der Heide, B., Hamel, L., \& Shulman, H. (2009). Self-generated versus othergenerated statements and impressions in computer-mediated communication: A test of warranting theory using Facebook. Communication Research, 36, 229-254.

Wang, S., Moon, S., Kwon, K., Evans, C., \& Stefanone, M. (2010). Face off: Implications of visual cues on Initiating friendship on Facebook. Computers in Human Behavior, 26, 226-234.

Webb, E. J.,Campbell, D. T., Schwartz, R. D., Sechrest, L., \& Grove, J. B. (1981). Nonreactive Measures in the Social Sciences. Boston: Houghton Mifflin.

Weisbuch, M., Ivevic, Z., \& Ambady, N. (2009). On being liked on the web and in the 'real world': Consistency in first impressions across personal webpages and spontaneous behavior. Journal of Experimental Social Psychology, 45, 573-576.

Wise, K., Alhabash, S., \& Park, H. (2010). Emotional responses during social information seeking on Facebook. Cyberpsychology, Behavior, and Social Networking, 13, 555-562.

Zimmer, M. (2010). "But the data is already public": On the ethics of research in Facebook. Ethics and Information Technology, 12.

Zywica, J., \& Danowski, J. (2008). The faces of facebookers: Investigating social enhancement and social compensation hypotheses; predicting Facebook ${ }^{\mathrm{TM}}$ and offline popularity from sociability and self-esteem, and mapping the meanings of popularity with semantic networks. Journal of Computer-Mediated Communication, 14, 1-34. 


\section{APPENDICES}

\section{Appendix A: Overview of Facebook Online Social Network}

Facebook consists of a series of interrelated profile pages in which members post a broad range of information about themselves and link their own profile to others' profiles. The core of the Facebook experience centers on users' ability to: (a) post self-relevant information on an individualized profile page; (b) link to other members and create a 'friends' list, and (c) interact with other members (Buffardi \& Cambell, 2008; Tufekci, 2008). Major features that promote communication include a "messages" system that allows for private communication and a "wall" system that allows for a more public form of communication (Grimmelmann, 2009). In addition, a 'Home' page provides a central hub where up-to-date information pertaining specifically to each user is displayed, including a personalized 'Events' calendar and a 'News Feed' where recent content contributions by friends are shown in chronological order. Users can post photographs and "tag" other users in photos, a feature so popular that, as of the time of writing, Facebook is the number one photo-sharing site in the world with 48 billion unique images (Fletcher, 2010; Lewis, Kaufman, \& Christakis, 2008b). With the click of a button, users can "poke" a friend (e.g., send a content-free notification of positive communication, rather like saying "Hi") or "like" a comment or picture (to indicate approval), presenting users with a quick and easy form of social interaction. Users can buy and sell items in the Marketplace and find entertainment on the Games page, and there are over 900 million objects that users can interact with in the form of pages, groups, events, and community pages (Facebook, 2011c).

A key organizational component of Facebook is the emphasis on networks, which define the users' levels of profile accessibility. The four broad categories of networks are colleges, high schools, workplaces, and regions, and users can access up to five networks (Lewis et al., 2008b). 
For many networks, Facebook allows access only to users with a valid email address that corresponds to a network. For example, only people with an @ state.edu address could gain access to the (hypothetical) State College network (Grimmelmann, 2008). Non-friend users within the same network are typically able to see more profile information than non-friend users outside of the network. Each network differs in the default level of access given to users within the network, and each user may personalize their privacy levels to restrict or open their profile. Thus, the network structure affects the ability of users to view the profile information of others. Perhaps the feature that most differentiates Facebook from other OSNs is the Facebook Platform, which allows third parties to develop Applications and permits other websites to integrate with Facebook through Open Graph (Gjoka, Sirivianos, Markopoulou, \& Yang, 2008). Applications are small programs designed specifically for Facebook that encompass a wide variety of forms including games, polls, quizzes, and fan pages. As of August 2011, there were over 550,000 applications with users installing an average of 20 million applications per day (Facebook, 2010; Facebook, 2011c).

Another key feature of the Facebook Platform is Open Graph, a utility that allows outside websites to seamlessly integrate with Facebook by placing a variety of Facebook features directly on any web page. For example, websites can choose to place a 'like' or 'recommend' button on a webpage, which allows Facebook users to express their approval of web content directly to their Facebook friends. This feature helps websites promote their content, and over 2.5 million websites have chosen to integrate with Facebook through Open Graph (Facebook, 2011c). With more than 250 million people engaging with Facebook on external websites every month, Open Graph has successfully positioned Facebook as a central hub for information sharing on the Internet (Facebook, 2011c). 


\section{Appendix B: Bibliography of Reports Included in the Review}

See page 57 to view the online supplementary materials, which includes the full bibliography of 410 articles.

\section{Appendix C: Data Collection Methods on Facebook}

The researchers cited in our literature review used three principle methods to collect Facebook data: Recruitment of participants in offline contexts, recruitment of participants via Facebook applications, and data crawling.

Recruitment of participants in offline contexts. Several studies recruited volunteers (often college students) in offline contexts. For example, to determine the percentage of users verses non-users, one early Facebook study used an offline survey, which was a necessary approach to capture a representative sample (Acquisti \& Gross, 2006). This method was especially effective when comparing offline and online behavior or when evaluating users verses non-users.

Recruitment of participants via Facebook applications. Facebook Inc. makes it simple for third party developers to create applications and surveys (see http://developers.facebook.com) and many researchers have taken advantage of this resource (e.g., Vajda, Ivanov, Goldmann, \& Ebrahimi, 2011). For example, one research team created three popular applications (Fighter's Club, Got Love, and Hugged) where users consented to sharing information when they download one of the applications (Nazir, Raza, \& Chuah, 2008). Combined, these three applications have over 8 million users, providing researchers with a huge dataset. MyPersonality, another example of a successful application used to collect data, is an online personality survey designed by 
psychologists. It provides an excellent model of how to construct a useful survey using a Facebook application (Stillwell \& Kosinski, 2011). Over 4.5 million users have taken the personality survey on this application, and the researchers have been able to gather a complex and detailed dataset. For example, the researchers released a database of triads where all three friends in the group are described with information on demographics, personality, selfmonitoring, IQ, workplace, education, and more (Stillwell \& Kosinski, 2011). MyPersonality demonstrates the vast potential of applications as a tool for recruiting participants on Facebook and studying interpersonal interactions. However, the success of applications is far from guaranteed. Some applications designed to collect data (e.g., youjustgetme) have been much less successful at recruiting participants than others (e.g., MyPersonality, MyType, Stumbl).

Data crawling. Data crawling, which involves gleaning information about users from their profiles without their active participation, provides another effective approach to gathering data from a wide range of users (Gjoka, Kurant, Butts, \& Markopoulou, 2011; Kurant, Markopoulou, \& Thiran, 2011). Data crawling is possible because researchers can implement algorithms to gather publicly available information from Facebook users (see Gjoka et al., 2011 for an excellent review of data crawling techniques). Note, however, that data crawling has become less informative over time as Facebook Inc. has implemented stricter privacy policies. As of March 2011, Facebook Inc. states that data cannot be collected using automated means (e.g., harvesting bots, robots, spiders, scrapers) without the explicit approval of Facebook Inc. (Facebook, 2011b).

The combination of recruiting participants (offline and through applications) and data crawling gives researchers some effective methods for gathering data on Facebook. In addition, investigators can take advantage of data already collected because several Facebook researchers 
have made their datasets available to the research community (Ginger, 2008; Nazir, Raza, Gupta, Chuah, \& Krishnamurthy, 2009; Stillwell \& Kosinski, 2011).

Ethical considerations. Before social scientists collect and examine Facebook data, it is imperative to consider the many ethical obligations inherent in Facebook research and OSN research more generally. One important debate has emerged regarding the appropriate methodological standards for research on Facebook. The heart of this discussion focuses on whether research on Facebook constitutes research with human subjects. Some ethics scholars contend that data mining projects harvest publically available data so they do not meet the regulatory definition of human subjects research, and therefore researchers should not have to gain approval from Institutional Review Boards (IRBs; Schrag, 2010; Solberg, 2010). However, this argument applies only to information that is publically available. Some users do set their privacy settings to allow access to everyone but many users opt for more restrictive privacy settings. If researchers are collecting private information or interacting with Facebook users, then there is an ethical obligation to adequately inform users about the research, gain their consent, and protect their information (Solberg, 2010).

Facebook and other OSNs constitute a new domain for research so it is understandable that protocols for research ethics have yet to be fully formalized. In the U.S., the Department of Health and Human Services is the federal agency charged with protecting the rights of human subjects in experiments and overseeing IRBs, but this agency has yet to issue formal guidance for research on Facebook (Solberg, 2010). In the absence of top-down direction, some IRBs have enacted institution-specific guidelines that apply to Facebook research (Solberg, 2010). In addition, because every user must register and accept the Facebook terms of use, certain user rights are explicitly protected by Facebook. For example, Facebook requires that any developer 
or operator of a Facebook application must obtain consent from users and explain what information is being collected and how the information will be used (Facebook, 2011b).

We urge caution and due diligence when conducting research on Facebook. The website Internet Research Ethics (internetresearchethics.org) provides an excellent resource for learning about current IRB standards and how they are being implemented in regards to Facebook. In addition, several articles examine ethical and methodological issues associated with gathering information on Facebook (see Buchanan \& Ess, 2011; Mazur, 2010; Solberg, 2010; Zimmer, 2010).

\section{Appendix D: Background on Facebook's privacy policies}

In December of 2009, Facebook unveiled a new 5,830-word Privacy Policy (Bilton, 2010). In addition to new granular privacy controls, Facebook changed the privacy default setting to allow everyone, including non-Facebook members, the ability to view profile information such as status updates, interests, and friends (Fletcher, 2010). The comprehensive change was lambasted by privacy advocates. Critics complained that the Privacy Policy was bewilderingly complicated, noting that a user must click through 50 privacy buttons and choose from 170 options in order to opt out of personal information disclosure (Bilton, 2010). In response to the growing public uproar, Facebook rolled out new, simplified privacy setting options in May of 2010 (Richmond, 2010). With the new settings, users could choose one of four overarching options regarding the people with which they wanted to share information - friends, friends of friends, everyone on the internet, or a 'recommended' option that combines settings from the three previous options. In addition, users could still change specific privacy options or micromanage their privacy settings if they did not wish to choose one of the overarching options. 
As this brief six-month snapshot demonstrates, the nature of Facebook's privacy policy frequently changes. Consequently, research results regarding privacy and information disclosure may be particularly dependent upon the time period in which the study was conducted. Facebook's privacy policy shifts have been well documented and a detailed summary and critique of events pre-2010 is available elsewhere (See Debatin, Lovejoy, Horn, \& Hughes, 2009).

\section{Privacy risks on Facebook}

To manage risk, a user must first understand the probability of a privacy breach occurring on Facebook. One notorious risk to Facebook users are botnets, which are false profiles that leverage social networks in order to spread malware, spam, and phish for user information. The most infamous botnet on Facebook is Koobface, which invites users to be their 'friend' and then attempts to trick users into installing malware by masquerading as a Flash update or other web link on a spoofed Facebook page (Thomas \& Nichol, 2010). Victims who fall for the ruse then automatically spam their own Facebook friends, perpetuating the cycle. In an attempt to assess the dangers posed by botnets, researchers created a Koobface botnet emulator to quantify the risk to Facebook users (Thomas \& Nichol, 2010). The study found that current defenses on Facebook recognize and block only $27 \%$ of threats and take on average 4 days to respond, which leaves Facebook users largely vulnerable to attacks. Obviously, botnets pose a major concern for Facebook users, and further research in this area is critical to mitigating the evolving threat of botnets.

Together, the research on privacy and disclosure on Facebook suggests three broad strategies for managing the risks found in this domain: (1) change the level of privacy from the permeable default setting to a more private setting, such as friends-only status, (2) limit the 
amount of personal information shared on Facebook, or (3) not acquire a Facebook account. The first step towards improving privacy management on Facebook is to further analyze the risks associated with using Facebook, and researchers must continue to pursue this goal. By better understanding the threats to privacy, researchers and developers can construct counter measures to mitigate the risks, and individual users can take informed steps toward protecting their personal information. 
Table 1

Areas of Facebook Research Identified in the Literature Review

\begin{tabular}{|c|c|c|c|}
\hline Categories of research & $\begin{array}{c}\text { \# of } \\
\text { articles }\end{array}$ & $\begin{array}{l}\% \text { of } \\
\text { total }\end{array}$ & Associated research question \\
\hline Descriptive analyses of users & 97 & $24 \%$ & $\begin{array}{l}\text { Who is using Facebook and what are users } \\
\text { doing while on Facebook? }\end{array}$ \\
\hline $\begin{array}{l}\text { Motivations for using } \\
\text { Facebook }\end{array}$ & 79 & $19 \%$ & Why do people use Facebook? \\
\hline Identity presentation & 50 & $12 \%$ & $\begin{array}{l}\text { How are people presenting themselves on } \\
\text { Facebook? }\end{array}$ \\
\hline $\begin{array}{l}\text { The role Facebook in social } \\
\text { interactions }\end{array}$ & 111 & $27 \%$ & $\begin{array}{l}\text { How is Facebook affecting relationships } \\
\text { among groups and individuals? }\end{array}$ \\
\hline $\begin{array}{l}\text { Privacy and information } \\
\text { disclosure }\end{array}$ & 73 & $18 \%$ & $\begin{array}{l}\text { Why are people disclosing personal } \\
\text { information on Facebook despite potential } \\
\text { risks? }\end{array}$ \\
\hline Total: & 410 & $100 \%$ & \\
\hline
\end{tabular}


Figure 1

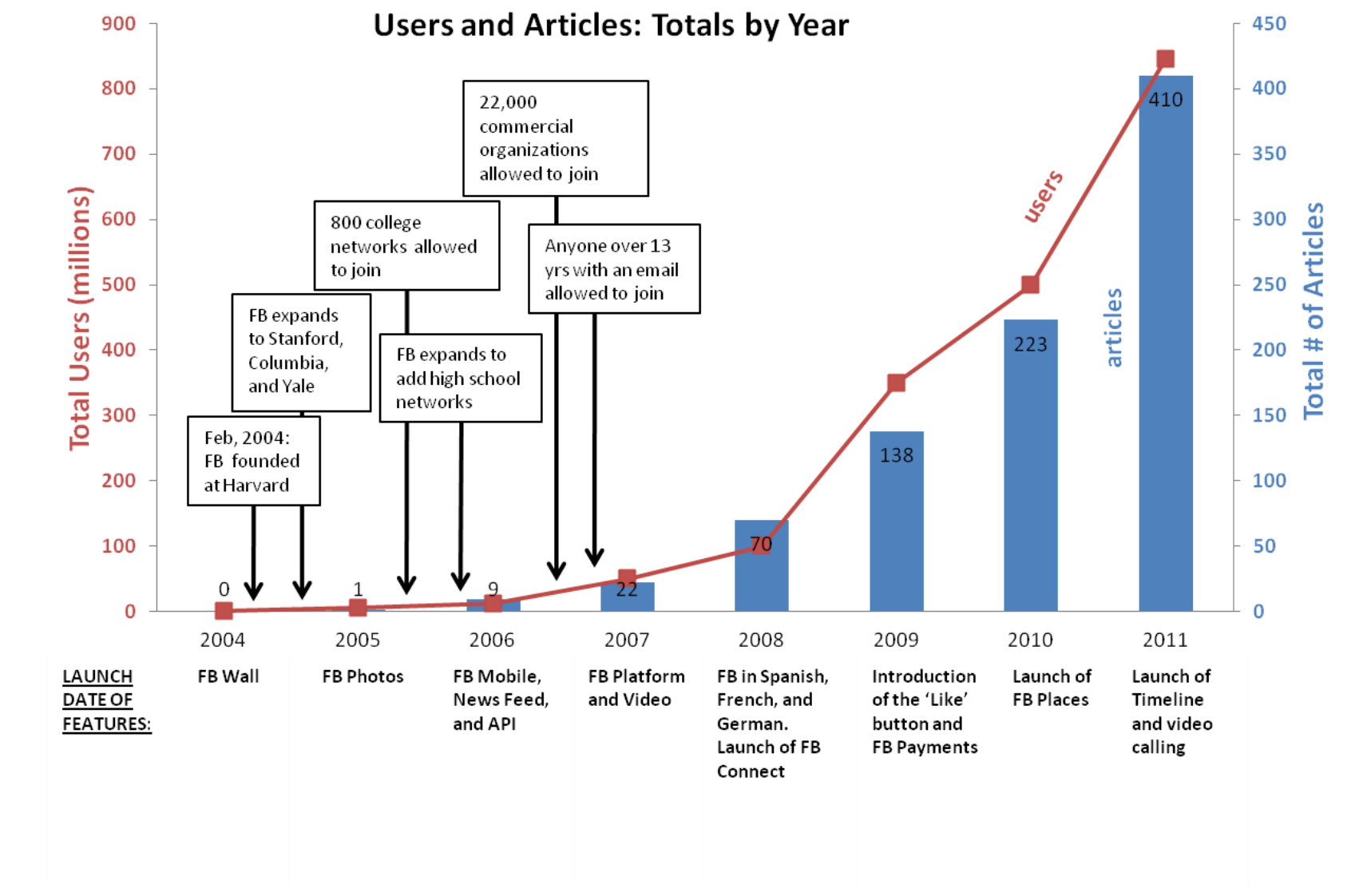


Online Supplemental Materials to accompany article:

\section{Appendix B: Bibliography of Reports Included in the Review}

Total articles: 410

Literature Review completed 01/01/12

\section{Literature Search procedures}

Our literature search used two basic steps: We first generated a large pool of potentially relevant articles and then selected a smaller subset of articles deemed relevant based on the three inclusion criteria described in the published manuscript. In the initial search cycle, we conducted searches in the PsycInfo, Google Scholar, Web of Science, and IEEE Xplore databases.

Our goal was to be as inclusive as possible, so we used the term "Facebook" as well as search terms such as "online social network" and "social network analysis" to identify other articles relating to Facebook that may not have explicitly used the term "Facebook" in the fields searched by keyword searches (e.g., the title, abstract, and list of keywords). This method yielded articles published primarily in peer-reviewed academic journals and conference proceedings, which was the focus of the review. After the initial search was completed, we reviewed the references cited by each relevant article and identified any new reports that were then included in a second round of articles to examine. This two-step approach yielded a wide range of articles relevant to Facebook. With each new relevant article, we browsed the references, searching for additional relevant articles, and continued this iterative process until no new relevant articles were found. The first exhaustive literature search was completed on January 1st, 2011, and this review served as the basis for the creation of our five theme-based categories. To provide the most thorough review for our readers and increase the usefulness of the bibliography, shortly 
before publication we updated our bibliography through January $1^{\text {st }}, 2012$. The follow-up literature search also served as a useful test for our 5-category structure. Given the magnitude and diversity of the article from 2011 (187 articles), the five categories proved to be a remarkably effective organizational framework. See Table S2 for a summary of articles published by category and year.

Note, we did not restrict our search to the social sciences and any articles that met the three inclusion criteria were included regardless of their disciplinary affiliation. So it is quite possible that our review captures every report written on Facebook, not just those in the social sciences. However, we did not specifically search databases focused on other disciplines such as Law and Management, so we restrict our claims to the social sciences.

The following bibliography is organized by category: Descriptive analyses of users (97 articles), motivations for using Facebook (79), identity presentation on Facebook (50), the role of Facebook on social interactions (111), and privacy and information disclosure (73).

\section{Descriptive Analyses of Users (97 articles)}

Ackland, R. (2009). Social network services as data sources and platforms for e-Researching social networks. Social Science Computer Review, 27, 481-492. doi: $10.1177 / 0894439309332291$

Akcora, C., Carminati, B., \& Ferrari, E. (2011). Network and profile based measures for user similarities on social networks. 2011 IEEE International Conference on Information Reuse and Integration, 292-298. doi: 10.1109/IRI.2011.6009562

Aral, S., \& Walker, D. (2011). Identifying social influence in networks using randomized experiments. IEEE Intelligent Systems, 26, 91-96. doi: 10.1109/MIS.2011.89 
Archibald, R., Liu, Y., Corbett, C., \& Ghosal, D. (2011). Disambiguating HTTP: Classifying web applications. 2011 7th International Wireless Communications and Mobile Computing Conference (IWCMC), 1808-1813. doi:

10.1109/IWCMC.2011.5982809

Backstrom, L., \& Kleinberg, J. (2011). Network bucket testing. Proceedings from WWW '11: The 20th international conference on World wide web. New York, NY, USA. doi: $10.1145 / 1963405.1963492$

Ballantine, P., \& Stephenson, R. (2011). Help me, I'm fat! Social support in online weight loss networks. Journal Of Consumer Behaviour, 10, 332-337. doi:10.1002/cb.374

Banhawi, F., \& Ali, N. (2011). Measuring user engagement attributes in social networking application. 2011 International Conference on Semantic Technology and Information Retrieval (STAIR), 297-301. doi: 10.1109/STAIR.2011.599580

Barkhuus, L., \& Tashiro, J. (2010). Student socialization in the age of facebook. Proceedings from the 28th international conference on Human factors in computing systems (CHI '10), 133-142. New York, NY, USA. doi:

$10.1145 / 1753326.1753347$

Bender, J., Jimenez-Marroquin, M., \& Jadad, A. (2011). Seeking support on facebook: A content analysis of breast cancer groups. Journal of medical Internet research, 13. doi:10.2196/jmir.1560

Bhattacharyya, P., Rowe, J., Wu, S., Haigh, K., Lavesson, N., \& Johnson, H. (2011). Your best might not be good enough: Ranking in collaborative social search engines. 20117 th International Conference on Collaborative Computing: Networking, Applications and Worksharing (CollaborateCom), 87-94. 
Caci, B., Cardaci, M., \& Tabacchi, M. (2010). Come è piccolo il mondo in rete: un'ipotesi smallworld sulla topologia di Facebook. Sistemi Intelligenti, 22, 451-457.

Castiglione, A., Cattaneo, G., \& De Santis, A. (2011). A forensic analysis of images on online social networks. 2011 Third International Conference on Intelligent Networking and Collaborative Systems, 679-684. doi: 10.1109/INCoS.2011.17

Catanese, S., De Meo, P., Ferrara, E., \& Fiumara, G. (2010). Analyzing the Facebook friendship graph. Proceedings CEUR Workshop '10: 1st International Workshop on Mining the Future Internet, 14-19.

Catanese, S., De Meo, P., Ferrara, E., Fiumara, G., \& Provetti, A. (2011). Crawling Facebook for social network analysis purposes. Proceedings from the International Conference on Web Intelligence, Mining and Semantics, 52.

Caviglione, L. (2011). Extending HTTP models to web 2.0 applications: The case of social networks. 2011 Fourth IEEE International Conference on Utility and Cloud Computing (UCC), 361-365. doi: 10.1109/UCC.2011.60

Chang, J., Rosenn I., Backstrom L., \& Marlow C. (2010). ePluribus: Ethnicity on Social Networks. Proceedings from the Fourth International Conference on Weblogs and Social Media (ICWSM-10), Washington, DC, USA.

Cvijikj, I., \& Michahelles, F. (2011). Monitoring trends on Facebook. IEEE Ninth International Conference on Dependable, Autonomic and Secure Computing (DASC), 895-902. doi: 10.1109/DASC.2011.150

Cvijikj, I., Spiegler, E., \& Michahelles, F. (2011). The effect of post type, category and posting day on user interaction level on Facebook. 2011 IEEE Third International Conference on 
Social Computing, 810-813.

doi:

10.1109/PASSAT/SocialCom.2011.21

Dantone, M., Bossard, L., Quack, T., \& van Gool, L. (2011). Augmented faces. IEEE International Conference on Computer Vision Workshops (ICCV Workshops), 24-31. doi: 10.1109/ICCVW.2011.6130218

De Meo, P., Ferrara, E., \& Fiumara, G. (2011). Finding similar users in Facebook. Social Networking and Community Behavior Modeling: Qualitative and Quantitative Measurement, 304-323. doi: 10.4018/978-1-61350-444-4.ch017

Dhillon, J. S., Ramos, C., Wunsche, B. C., \& Lutteroth, C. (2011). Designing a web-based telehealth system for elderly people: An interview study in New Zealand. 2011 24th International Symposium on Computer-Based Medical Systems (CBMS), 1-6. doi: 10.1109/CBMS.2011.5999157

Doroud, M., Bhattacharyya, P., Wu, S. F., \& Felmlee, D. (2011). The evolution of ego-centric triads: A microscopic approach toward predicting macroscopic network properties. 2011 IEEE Third International Conference on on Social Computing (SocialCom), 172-179.

Effendy, S., Halim, F., \& Yap, R. (2011). Partial social network disclosure and crawlers. 2011 IEEE Ninth International Conference on Dependable, Autonomic and Secure Computing (DASC), 808-815. doi: 10.1109/DASC.2011.139

Egan K., \& Moreno, M. (2011). Prevalence of stress references on college freshmen Facebook profiles. Computers, Informatics, Nursing, 29, 586-592. doi: 10.1097/NCN.0b013e3182160663

Fire, M., Tenenboim, L., Lesser, O., Puzis, R., Rokach, L., \& Elovici, Y. (2011). Link prediction in social networks using computationally efficient topological features. 2011 IEEE Third 
International Conference on Privacy, Security, Risk and Trust (PASSAT), 73-80. doi:

10.1109/PASSAT/SocialCom.2011.20

Gjoka, M., Sirivianos, M., Markopoulou, A., \& Yang, X. (2008). Poking Facebook:

Characterization of OSN Applications. Proceedings from the first workshop on Online social networks. Seattle, WA, USA. doi: 10.1145/1397735.1397743

Gjoka, M., Kurant, M., Butts, C.T., \& Markopoulou, A. (2010). Walking in Facebook: A Case Study of Unbiased Sampling of OSNs. Proceedings from INFOCOM. San Diego, CA, USA. doi: 10.1109/INFCOM.2010.5462078

Gjoka, M., Kurant, M., Butts, C., \& Markopoulou, A. (2011). Practical recommendations on crawling online social networks. IEEE Journal on Selected Areas in Communications, 29, 1872-1892. doi: 10.1109/JSAC.2011.111011

Goel, S., Mason, W. \& Watts, D. (2010). Real and Perceived Attitude Agreement in Social Networks. Journal of Personality and Social Psychology, 99, 611-621. doi: $10.1037 / \mathrm{a} 0020697$

Golder, S. A., Wilkinson, D., \& Huberman, B. A. (2007). Rhythms of social interaction: Messaging within a massive online network. In C. Steinfield, B. Pentland, M. Ackerman, \& N. Contractor (Eds.), Communities and Technologies 2007: Proceedings from the Third International Conference on Communities and Technologies, London, England.

Gonzales, A. L., \& Hancock, J. T. (2011). Mirror, mirror on my Facebook wall: Effects of exposure to Facebook on self-esteem. Cyberpsychology, Behavior, And Social Networking, 14, 79-83. doi:10.1089/cyber.2009.0411

Gosling, S. D., Augustine, A. A., Vazire, S., Holtzman, N., \& Gaddis, S. (2011). Manifestations of personality in online social networks: Self-reported Facebook-related behaviors and 
observable profile information. Cyberpsychology, Behavior, And Social Networking, 14, 483-488. doi:10.1089/cyber.2010.0087

Greene, J. A., Choudhry, N. K., Kilabuk, E., \& Shrank, W. H. (2011). Online social networking by patients with diabetes: A qualitative evaluation of communication with Facebook. Journal of General Internal Medicine, 26, 287-292. doi: 10.1007/s11606-010$1526-3$

Hagger-Johnson, G., Egan, V., \& Stillwell, D. (2010). Are social networking profiles reliable indicators of sensational interests?. Journal Of Research In Personality, 45, 71-76. doi:10.1016/j.jrp.2010.11.013

Halim, F., Yap, R., \& Wu, Y. (2011). A MapReduce-based maximum-flow algorithm for large small-world network graphs. 201131 st International Conference on Distributed Computing Systems (ICDCS), 192-202. doi: 10.1109/ICDCS.2011.6

Han, L., Nath, B., Iftode, L., \& Muthukrishnan, S. (2011). Social butterfly: Social caches for distributed social networks. 2011 IEEE Third International Conference on Privacy, Security, Risk and Trust (PASSAT), 81-86. doi:

10.1109/PASSAT/SocialCom.2011.105

Hargittai, E. (2007). Whose space? Differences among users and non-users of social network sites. Journal of Computer-Mediated Communication, 13, 276-297. doi: 10.1111/j.1083-6101.2007.00396.x

He, Y., Lee, R., Huai, Y., Shao, Z., Jain, N., Zhang, X., \& Xu, Z. (2011). RCFile: A fast and space-efficient data placement structure in MapReduce-based warehouse systems. 2011 IEEE 27th International Conference on Data Engineering (ICDE), 1199-1208. doi: 10.1109/ICDE.2011.5767933 
Hossmann, T., Legendre, F., Nomikos, G., \& Spyropoulos, T. (2011). Stumbl: Using Facebook to collect rich datasets for opportunistic networking research. 2011 IEEE International Symposium on a World of Wireless, Mobile and Multimedia Networks, 1-6. doi:

10.1109/WoWMoM.2011.5986142

Hsu, C., Wang, C., \& Tai, Y. (2011). The closer the relationship, the more the interaction on Facebook? Investigating the case of Taiwan users. Cyberpsychology, Behavior, And Social Networking, 14, 473-476. doi:10.1089/cyber.2010.0267

Jahanbakhsh, K., King, V., \& Shoja, G. C. (2011). Empirical comparison of information spreading algorithms in the presence of 1-Whiskers. 2011 IEEE Third International Conference on Privacy, Security, Risk and Trust (PASSAT), 489-492. doi:

10.1109/PASSAT/SocialCom.2011.112

Judd, T. (2010). Facebook verses email. British Journal of Educational Technology, 41, 101103. doi: 10.1111/j.1467-8535.2009.01041.x

Judd, T., \& Kennedy, G. (2010). A five-year study of on-campus internet use by undergraduate biomedical students. Computers \& Education, 55, 1564-1571. doi: 10.1016/j.compedu.2010.06.022

Kalpidou, M., Costin, D., \& Morris, J. (2011). The relationship between Facebook and the wellbeing of undergraduate college students. Cyberpsychology, Behavior, And Social Networking, 14, 183-189. doi:10.1089/cyber.2010.0061

Karl, K., Peluchette, J., \& Schlaegel, C. (2010). A cross-cultural examination of student attitudes and gender differences in Facebook profile content. International Journal of Virtual Communities and Social Networking, 2, 11-31. doi: 10.4018/jvcsn.2010040102 
Kirman, B., Lawson, S., \& Linehan, C. (2009). Gaming on and off the Social Graph: The social structure of Facebook Games. International Conference on Computational Science and Engineering, Miami, FL, USA. doi: 10.1109/CSE.2009.266

Kramer, A. (2010). An unobtrusive behavioral model of "gross national happiness." Conference on Human Factors in Computing '10, Atlanta, GA, USA. doi: $10.1145 / 1753326.1753369$

Kujath, C. L. (2011). Facebook and MySpace: Complement or substitute for face-to-face interaction?. Cyberpsychology, Behavior, And Social Networking, 14, 75-78. doi:10.1089/cyber.2009.0311

Kurant, M., Markopoulou, A., \& Thiran, P. (2010). On the bias of BFS (Breadth First Search). 22nd International Teletraffic Congress (ITC).

Kurant, M., Markopoulou, A., \& Thiran, P. (2011). Towards unbiased BFS sampling. IEEE Journal on Selected Areas in Communications, 29, 1799-1809. doi: 10.1109/JSAC.2011.111005

Lampe, C., Ellison, N., \& Steinfield, C. (2008). Changes in use and perception of Facebook. Proceedings from the 2008 ACM conference on Computer supported cooperative work, San Diego, CA, USA. doi: 10.1145/1460563.1460675

Lee, J. W. Y, Kim, B., \& Kim, M. S. (2011). Creating the intercultural learning narrative using social network sites status updates: An innovative approach in using social media. Global Learn Asia Pacific 2011, 1819-1826.

Lee, M., Weng, M., Lin, C., Ma, Z., Lin, J., \& Lin, L. (2011). General pattern discovery for development of social game-based learning: A case study from games in Facebook. 2011 
4th International Conference on Ubi-Media Computing (U-Media), 95-100. doi:

10.1109/U-MEDIA.2011.49

Lewis, K., Kaufman, J., Gonzalez, M., Wimmer, A., \& Christakis, N. (2008). Taste, ties, and time: A new dataset using Facebook.com. Social Networks, 30, 330-342. doi: 10.1016/j.socnet.2008.07.002

Li, Z., Zhou, D., Juan, Y., \& Han, J. (2010). Keyword extraction for social snippets. Proceeding of the 19th international conference on World Wide Web, Raleigh, NC, USA.

Li, L. (2011). Social network sites comparison between the United States and China: Case study on facebook and renren network. 2011 International Conference on Business Management and Electronic Information (BMEI), 1, 825-827.

doi: 10.1109/ICBMEI.2011.5917063

Lord, S., Brevard, J., \& Budman, S. (2011). Connecting to young adults: An online social network survey of beliefs and attitudes associated with prescription opioid misuse among college students. Substance Use \& Misuse, 46, 66-76.

doi:10.3109/10826084.2011.554351

Martinsen, J. K., \& Grahn, H. (2011). Methodology for evaluating JavaScript execution behavior in interactive web applications. 2011 9th IEEE/ACS International Conference on Computer Systems and Applications, 241-248.

doi: 10.1109/AICCSA.2011.6126611

McCorkindale, T. (2010). Can you see the writing on my wall? A content analysis of the Fortune 50’s Facebook Social Networking Sites. Public Relations Journal, 4. 
Mohaisen, A., Hopper, N., \& Kim, Y. (2011). Keep your friends close: Incorporating trust into social network-based Sybil defenses. 2011 Proceedings from IEEE INFOCOM, 19431951. doi: 10.1109/INFCOM.2011.5934998

Nazir, A., Raza, S., \& Chuah, C. (2008). Unveiling Facebook: A measurement study of social network based applications. Proceedings from the 8th ACM SIGCOMM conference on Internet measurement. Vouliagmeni, Greece. doi: $10.1145 / 1452520.1452527$

Nazir, A., Raza, S., Gupta, D., Chuah, C., \& Krishnamurthy, B. (2009). Network level footprints of facebook applications. Proceedings from the 9th ACM SIGCOMM conference on Internet measurement conference (IMC '09), 63-75. New York, NY, USA. doi: $10.1145 / 1644893.1644901$

Nguyen, K., Pham, C., Tran, D. A., \& Zhang, F. (2011). Preserving social locality in data replication for online social networks. 2011 31st International Conference on Distributed Computing Systems Workshops (ICDCSW), 129-133. doi:

10.1109/ICDCSW.2011.14

Nguyen, K., \& Tran, D. A. (2011). An analysis of activities in Facebook. 2011 IEEE Consumer Communications and Networking Conference (CCNC), 388-392. doi: 10.1109/CCNC.2011.5766497

Nguyen, N., Dinh, T., Xuan, Y., \& Thai, M. (2011). Adaptive algorithms for detecting community structure in dynamic social networks. 2011 Proceedings from IEEE INFOCOM, 2282-2290. doi: 10.1109/INFCOM.2011.5935045

Pakzad, F., \& Abhari, A. (2010). Characterization of user networks in Facebook. In Proceedings from the 2010 Spring Simulation Multiconference (SpringSim '10), ACM, New York, 
NY, USA, Article 105. doi: 10.1145/1878537.1878647

Papacharissi, Z. (2009). The virtual geographies of social networks: A comparative analysis of Facebook, LinkedIn and ASmallWorld. New Media and Society, 11, 199-220. doi: $10.1177 / 1461444808099577$

Pempek, T., Yermolayeva, Y., \& Calvert, S. (2009). College students' social networking experiences on Facebook. Journal of Applied Developmental Psychology, 30, 227-238. doi: 10.1016/j.appdev.2008.12.010

Pinto, N., Stone, Z., Zickler, T., \& Cox, D. (2011). Scaling up biologically-inspired computer vision: A case study in unconstrained face recognition on facebook. 2011 IEEE Computer Society Conference on Computer Vision and Pattern Recognition Workshops (CVPRW), 35-42. doi: 10.1109/CVPRW.2011.5981788

Quinn, D., Chen, L., \& Mulvenna, M. (2011). Does age make a difference in the behaviour of online social network users?. 2011 International Conference on Internet of Things and 4th International Conference on Cyber, Physical and Social Computing, 266-272. doi: 10.1109/iThings/CPSCom.2011.86

Ranjbar, A., \& Maheswaran, M. (2011). Blocking in community-centric information management approaches for the social web. 2011 IEEE Global Telecommunications Conference (GLOBECOM 2011), 1-5. doi:

\subsection{9/GLOCOM.2011.6134411}

Reid, F., McDaid, A., \& Hurley, N. (2011). Partitioning breaks communities. 2011 International Conference on Advances in Social Networks Analysis and Mining (ASONAM), 102-109. doi: 10.1109/ASONAM.2011.36 
Robelia, B. A., Greenhow, C., \& Burton, L. (2011). Environmental learning in online social networks: Adopting environmentally responsible behaviors. Environmental Education Research, 17, 553-575. doi:10.1080/13504622.2011.565118

Ruder, T. D., Hatch, G. M., Ampanozi, G., Thali, M. J., \& Fischer, N. (2011). Suicide announcement on Facebook. Crisis: The Journal Of Crisis Intervention And Suicide Prevention, 32, 280-282. doi:10.1027/0227-5910/a000086

Ryan, T., \& Xenos, S. (2011). Who uses Facebook? An investigation into the relationship between the Big Five, shyness, narcissism, loneliness, and Facebook usage. Computers In Human Behavior, 27, 1658-1664. doi:10.1016/j.chb.2011.02.004

Saleh, F., Jani, H., Marzouqi, M., Khajeh, N., \& Rajan, A. (2011). Social networking by the youth in the UAE: A privacy paradox. 2011 International Conference and Workshop on Current Trends in Information Technology, 28-31.

doi: 10.1109/CTIT.2011.6107957

Schiotz, N., Schmidt, \& Bo, S. (2010). Digital connections and new awareness: An ethnographic study of Facebook. Dansk Sociologi, 21, 9-26.

Shen, K. N., \& Khalifa, M. (2010). Facebook usage among Arabic college students: preliminary findings on gender differences. International Journal of E-Business Management, 4.

Sibona, C., \& Walczak, S. (2011). Unfriending on Facebook: Friend request and online/offline behavior analysis. 44th Hawaii International Conference on System Sciences, 1-10. doi: 10.1109/HICSS.2011.467

Steafnone, M., Huang, Y., \& Lackaff, D. (2011). Negotiating social belonging: Online, offline, and in-between. 2011 44th Hawaii International Conference on System Sciences, 1-10. doi: 10.1109/HICSS.2011.314 
Stefanone, M., Lackaff, D., \& Rosen, D. (2011). Contingencies of self-worth and socialnetworking-site behavior. Cyberpsychology, Behavior, And Social Networking, 14, 41-49. doi:10.1089/cyber.2010.0049

Stutzman, F. (2008). Longitudinal analysis of freshman adoption of Facebook.com. iConference 2008, Los Angeles, CA, USA.

Sumner, C., Byers, A., \& Shearing, M. (2011). Determining personality traits \& privacy concerns from Facebook activity. Black Hat Briefings '11. Abu Dhabi, United Arab Emirates.

Tang, C., Ross, K., Saxena, N., \& Chen, R. (2011). What's in a name: A study of names, gender inference, and gender behavior in Facebook. Proceedings from SNSMW '11: Workshop on Social Networks and Social Media Mining on the Web. Hong Kong, China.

Thalmayer, A., Saucier, G., \& Eigenhuis, A. (2011). Comparative validity of brief to mediumlength Big Five and Big Six personality questionnaires. Psychological Assessment, 23, 995-1009. doi:10.1037/a0024165

Torok, R. (2011). The online institution: Psychiatric power as an explanatory model for the normalisation of radicalisation and terrorism. 2011 European Intelligence and Security Informatics Conference (EISIC), 78-85. doi: 10.1109/EISIC.2011.43

Trentacosti, F. (2011). Social capital, happiness and social networking sites. Surfing alone: Do countries with higher numbers of users in online communities have higher happiness levels?. IEEE Computer Society. Retrieved on February 6, 2012 from http://www.socialcapitalgateway.org/sites/socialcapitalgateway.org/files/ data/phdthesis/2011/12/08/socialcapitalhappinessandsocialnetworkingsitesfabriziotrentacosti-mscdevelopmenteconomics.pdf 
Tsoi, H. K., \& Chen, L. (2011). From privacy concern to uses of social network sites: A cultural comparison via user survey. 2011 IEEE Third International Conference on Privacy, Security, Risk and Trust (PASSAT), 457-464.

Tu, B., Wu, H., Hsieh C., \& Chen, P. (2011). Establishing new friendships-from Face-to-Face to Facebook: A case study of college students. 2011 44th Hawaii International Conference on System Sciences (HICSS), 1-10. doi: 10.1109/HICSS.2011.192

Vajda, P., Ivanov, I., Goldmann, L., \& Ebrahimi, T. (2011). Social game epitome versus automatic visual analysis. 2011 IEEE International Conference on Multimedia and Expo, 1-6. doi: 10.1109/ICME.2011.6011927

Wilson, C., Boe, B., Sala, A., Puttaswamy, K. P., \& Zhao, B. Y. (2009). User interactions in social networks and their implications. In EuroSys '09: Proceedings from the 4th ACM European conference on Computer systems, 205-218. doi: $10.1145 / 1519065.1519089$

Wimmer, A., \& Lewis, K. (2010). Beyond and below racial homophily: ERG models of a friendship network documented on Facebook. American Journal of Sociology, 116, 583642. doi: $10.1086 / 653658$

Wise, L., \& Williams, B. (2011). Facebook in higher education promotes social but not academic engagement. Proceedings from ascilite 2011 Hobart. Wrest Point, Australia.

Xu, B., \& Liu, L. (2010). Information diffusion through online social networks. IEEE International Conference on Emergency Management and Management Sciences. Beijing, China. doi: 10.1109/ICEMMS.2010.5563505 
Zhan, J., Jones, N., \& Purnell, M. (2011). Top-K algorithm for recommendation in social networking kingdoms. 2011 IEEE Third International Conference on Privacy, Security, Risk and Trust, 688-694. doi: 10.1109/PASSAT/SocialCom.2011.233

Zhang, S., Jiang, H., \& Carroll, J. M. (2011). Integrating online and offline community through Facebook. 2011 International Conference on Collaboration Technologies and Systems (CTS), 569-578. doi: 10.1109/CTS.2011.5928738

Zorica, M. B., Biskupic, I. O., Ivanjko, T., \& Spiranec, S. (2011). Students and privacy in the networked environment. 2011 Proceedings from the 34th International Convention MIPRO, 1090-1094.

\section{Motivations for Using Facebook (79 articles)}

Amichai-Hamburger, Y., \& Vinitzky, G. (2010). Social network use and personality. Computers in Human Behavior, 26, 1289-1295. doi: 10.1016/j.chb.2010.03.018

Backstrom, L., Sun, E., \& Marlow, C. (2010). Find me if you can: improving geographical prediction with social and spatial proximity. Proceedings from the 19th international Conference on World Wide Web, Raleigh, North Carolina, USA. doi:

$10.1145 / 1772690.1772698$

Baek, K., Holton, A., Harp, D., \& Yaschur, C. (2011). The links that bind: Uncovering novel motivations for linking on Facebook. Computers In Human Behavior, 27, 2243-2248. doi:10.1016/j.chb.2011.07.003

Baker, L., \& Oswald, D. (2010). Shyness and online social networking services. Journal Of Social And Personal Relationships, 27, 873-889. doi:10.1177/0265407510375261 
Banhawi, F., Ali, N., \& Judi, H. (2011). Measuring user engagement levels in social networking application. 2011 International Conference on Electrical Engineering and Informatics, 16. doi: 10.1109/ICEEI.2011.6021638

Bonds-Raacke, J., \& Raacke, J. (2010). MySpace and Facebook: Identifying dimensions of uses and gratifications for friend networking sites. Individual Differences Research, 8, 27-33. doi: $10.1089 / \mathrm{cpb} .2007 .0056$

Bumgarner, B. (2007). You have been poked: Exploring the uses and gratifications of Facebook among emerging adults. First Monday, 12.

Burke, M., Kraut, R., \& Marlow, C. (2011). Social capital on Facebook: Differentiating uses and users. ACM CHI 2011: Conference on Human Factors in Computing Systems, 571-580.

Burke, M., Marlow, C., \& Lento, T. (2009). Feed me: motivating newcomer contribution in social network sites. Proceedings from the 27th international conference on Human factors in computing systems. Boston, MA, USA. doi: 10.1145/1518701.1518847

Burke, M., Marlow, C., \& Lento, T. (2010). Social network activity and social well-being. Postgrad Med Journal, 85, 455-459. doi: 10.1145/1753326.1753613

Carpenter, J., Green, M., \& LaFlam, J. (2011). People or profiles: Individual differences in online social networking use. Personality And Individual Differences, 50, 538-541. doi:10.1016/j.paid.2010.11.006

Chang, S. C., \& Liu, P. H. (2011). Using focus group to investigate why people use facebook: The case of Taiwan. Proceedings from PICMET '11: Technology Management in the Energy Smart World, 1-6. 
Cheung, C., Chiu, P., \& Lee, M. (2011). Online social networks: Why do students use Facebook?. Computers In Human Behavior, 27, 1337-1343. doi:10.1016/j.chb.2010.07.028

Cheung, C., \& Lee, M. (2010). A theoretical model of intentional social action in online social networks. Decision Support Systems, 49, 24-30.

doi: 10.1016/j.dss.2009.12.006

Chiu, P., Cheung, C., \& Lee, M. (2008). Online social networks: Why do "We" use Facebook?. Communications in Computer and Information Science, 19, 67-74.

Davis, S., Burnett, I., \& Ritz, C. (2009). Using social networking and collections to enable video semantics acquisition. IEEE International Conference on Multimedia \& Expo. New York, NY, USA. doi: 10.1109/MMUL.2009.72

Ellison, N., Steinfield, C., \& Lampe, C. (2006). Spatially bounded online social networks and social capital: The role of Facebook. Proceedings from the annual conference of the international communication association. Dresden, Germany.

Ellison, N., Steinfield, C., \& Lampe, C. (2007). The benefits of Facebook 'friends:' Social capital and college students' use of online social network sites. Journal of ComputerMediated Communication, 12, 1143-1168. doi: 10.1111/j.1083-6101.2007.00367.x

Ellison, N., Steinfield, C., \& Lampe, C. (2011). Connection strategies: Social capital implications of Facebook-enabled communication practices. New Media \& Society, 13, 873-892. doi: 10.1177/1461444810385389

Erickson, L. (2011). Social media, social capital, and seniors: The impact of Facebook on bonding and bridging social capital of individuals over 65. Americas Conference on Information Systems, Paper 85. Detroit, MI, USA. 
Ferebee, S., \& Davis, J. (2009). Factors that persuade continued use of Facebook among new members. Proceedings from the 4th International Conference on Persuasive Technology (Persuasive '09), ACM, New York, NY, USA, Article $35 . \quad$ doi: $10.1145 / 1541948.1541994$

Fogg, B. J., \& Iizawa, D. (2008). Online persuasion in Facebook and Mixi: A cross-cultural comparison. Proceedings from the 3rd international conference on Persuasive Technology. Oulu, Finland. doi: 10.1007/978-3-540-68504-3_4

Gangadharbatla, H. (2008). Facebook me: collective self-esteem, need to belong, and internet self-efficacy as predictors of the iGeneration attitudes toward social networking sites. Journal of Interactive Advertising, 8.

Gilbert, E., \& Karahalios, K. (2009). Predicting tie strength with social media. Proceedings from the 27th international conference on Human factors in computing systems, Boston, MA. doi: $10.1145 / 1518701.1518736$

Gomes, A. K., \& Pimentel, M. (2011). Social interactions representation as users behavioral contingencies and evaluation in social networks. 2011 Fifth IEEE International Conference on Semantic Computing (ICSC), 275-278. doi: 10.1109/ICSC.2011.103

Hsu, C., \& Wu, C. (2011). Understanding users' continuance of Facebook: An integrated model with the unified theory of acceptance and use of technology, expectation disconfirmation model, and flow theory. International Journal of Virtual Communities and Social Networking (IJVCSN), 3, 1-16. doi:10.4018/jvcsn.2011040101 
Huang, S., \& Lee, D. (2011). Exploring structural features in predicting social network evolution. 2011 10th International Conference on Machine Learning and Applications and Workshops (ICMLA), 2, 269-274. doi: 10.1109/ICMLA.2011.66

Hyllegard, K. H., Ogle, J., Yan, R., \& Reitz, A. R. (2011). An exploratory study of college students' fanning behavior on Facebook. College Student Journal, 45, 601-616.

Ito, M., Baumer, S., Bittanti, M., boyd, d., Cody, R., Herr-Stephenson, B., Horst, H., Lange, P., Mahendran, D., Martínez, K., Pascoe, C., Perkel, D., Robinson, L., Sims, C., \& Tripp, L. (2010) Hanging Out, Messing Around, and Geeking Out: Kids Living and Learning with New Media. Cambridge, Mass.: The MIT Press.

Joinson, A. N. (2008). Looking at, looking up or keeping up with people?: Motives and use of facebook. CHI '08: Proceeding of the twenty-sixth annual SIGCHI conference on Human factors in computing systems, 1027-1036. New York, NY, USA. doi: $10.1145 / 1357054.1357213$

Kim, J., Kim, M., \& Nam, Y. (2010). An analysis of self-construals, motivations, Facebook use, and user satisfaction. International Journal of Human-Computer Interaction, 26, 10771099.

Kirman, B., Lawson, S., Linehan, C., Martino, F., Gamberini, L., \& Gaggioli, A. (2010). Improving social game engagement on facebook through enhanced socio-contextual information. Proceedings from the 28th international conference on Human factors in computing systems (CHI '10), ACM, New York, NY, USA, 1753-1756. doi:

$10.1145 / 1753326.1753589$ 
Koroleva, K., Krasnova, H., Veltri, N., \& Günther, O. (2011). It’s all about networking! Empirical investigation of social capital formation on social network sites. Proceeding from ICIS 2011, Paper 24.

Lampe, C., Ellison, N., \& Steinfield, C. (2006). A Face(book) in the Crowd: Social Searching vs. Social Browsing. Paper presented at the ACM Special Interest Group on ComputerSupported Cooperative Work, Banff, Canada. doi: $10.1145 / 1180875.1180901$

Lampe, C., Ellison, N., \& Steinfield, C. (2007). A familiar Face(book): Profile elements as signals in and online social network. CHI 2007 Proceedings. San Jose, CA, USA.

LaRose, R., Wohn, D. Y., Ellison, N. \& Steinfield, C. (2011). Facebook fiends: Compulsive social networking and adjustment to college. Presented at IADIS Multiconference on Computer Science and Information Systems. Rome, Italy.

Lee, J. W. Y., Kim, B., \& Kim, M. S. (2010). An exploration on the use of Facebook as a tool for social support during an intercultural exchange program. Global Learn Asia Pacific 2010.

Lee, K. H., Lippman, A., Pentland, A. S., \& Dugundji, E. R. (2011). The impacts of just-in-time social networks on people's choices in the real world. 2011 IEEE Third International Conference on Privacy, Security, Risk and Trust (PASSAT), 9-18. doi: 10.1109/PASSAT/SocialCom.2011.137

Lewis, J., \& West, A. (2009). 'Friending': London-based undergraduates' experience of Facebook. New Media \& Society, 11, 1209-1229. doi: 10.1145/1240624.1240695

Lin, K., \& Lu, H. (2011). Intention to continue using Facebook fan pages from the perspective of social capital theory. Cyberpsychology, Behavior, And Social Networking, 14, 565-570. doi:10.1089/cyber.2010.0472 
Litt, D. M., \& Stock, M. L. (2011). Adolescent alcohol-related risk cognitions: The roles of social norms and social networking sites. Psychology Of Addictive Behaviors, 25, 708 713. doi: $10.1037 / \mathrm{a} 0024226$

Mauri, M., Cipresso, P., Balgera, A., Villamira, M., \& Riva, G. (2011). Why is Facebook so successful? Psychophysiological measures describe a core flow state while using Facebook. Cyberpsychology, Behavior \& Social Networking, 14, 723-731. doi:10.1089/cyber.2010.0377

Mayer, A., \& Puller, S. L. (2008). The old boy (and girl) network: social network formation on university campuses. Journal of Public Economics, 92, 329-347. doi: 10.1016/j.jpubeco.2007.09.001

Muise, A., Christofides, E., \& Desmarais, S. (2009). More information than you ever wanted: Does Facebook bring out the green-eyed monster of jealousy? CyberPsychology \& Behavior, 12, 441-444. doi: 10.1089/cpb.2008.0263.

Newman, M. W., Lauterbach, D., Munson, S. A., Resnick, P., \& Morris, M. E. (2011). It's not that I don't have problems, I'm just not putting them on facebook: Challenges and opportunities in using online social networks for health. In Proceedings from CSCW $2011,341-350$.

Orr, E. S., Sisic, M., Simmering, M.G., \& Arseneault, J. M. (2009). The influence of shyness on the use of Facebook in an undergraduate sample. CyberPsychology \& Behavior, 12, 337 340. doi: 10.1089/cpb.2008.0214.

Pan, S. J., Boston, D. J., \& Borcea, C. (2011). Analysis of fusing online and co-presence social networks. 2011 IEEE International Conference on Pervasive Computing and 
Communications Workshops (PERCOM Workshops), 496-501.

doi: 10.1109/PERCOMW.2011.5766940

Papacharissi, Z., \& Mendelson, A. (2011). Toward a new(er) sociability: Uses, gratifications and social capital on Facebook. Media Perspectives for the 21st Century, Stelios Papathanassopoulos (Ed.), Routledge, 212-230.

Park, N., Kee, K., \& Valenzuela, S. (2009). Being immersed in social networking environment: Facebook groups, uses and gratifications, and social outcomes. CyberPsychology \& Behavior, 12. doi: 10.1089/cpb.2009.0003.

Quan-Haase, A. \& Young, A. (2010). Uses and gratifications of social media: A comparison of Facebook and instant messaging. Bulletin of Science, Technology and Society, 30, 350361. doi: 10.1177/0270467610380009

Rosen, P., \& Sherman, P. (2006). Hedonic information systems: Acceptance of social networking websites. Proceedings from the Twelfth Americas Conference on Information Systems. Acapulco, Mexico.

Ross, C., Orr, E. S., Sisic, M., Arseneault, J. M., Simmering, M. G., \& Orr, R. R. (2009). Personality and motivations associated with Facebook use. Computers in Human Behavior, 25, 578-586. doi: 10.1016/j.chb.2008.12.024

Sas, C., Dix, A., Hart, J., \& Su, R. (2009). Dramaturgical capitalization of positive emotions: The answer for Facebook success?. Proceedings from the 23rd British HCI Group Annual Conference on People and Computers: Celebrating People and Technology (BCS-HCI '09), British Computer Society, Swinton, UK, 120-129. 
Sheldon, K. M., Abad, N., \& Hinsch, C. (2011). A two-process view of Facebook use and relatedness need-satisfaction: Disconnection drives use, and connection rewards it. Journal Of Personality And Social Psychology, 100, 766-775. doi:10.1037/a0022407

Sheldon, P. (2008a). Student favorite: Facebook \& motives for its use. Southwestern Journal of Mass Communication, 23, 39-55.

Sheldon, P. (2008b). The relationship between unwillingness-to-communicate and students' Facebook use. Journal of Media Psychology: Theories, Methods, and Applications, 20, 67-75. doi: 10.1027/1864-1105.20.2.67

Shi, N., Lee, M. K. O., Cheung, C., \& Chen, H. (2010). The continuance of online social networks: How to keep people using Facebook?. 43rd Hawaii International Conference on System Sciences. Honolulu, HI, USA. doi:

10.1109/HICSS.2010.369

Smock, A. D., Ellison, N. B., Lampe, C., \& Wohn, D. (2011). Facebook as a toolkit: A uses and gratification approach to unbundling feature use. Computers In Human Behavior, 27, 2322-2329. doi:10.1016/j.chb.2011.07.011

Steinfeld, C., DiMicco, J., Ellison, N., \& Lampe, C. (2009). Bowling online: social networking and social capital within the organization. Proceedings from the Fourth International Conference on Communities and Technologies (C\&T 2009), State College, PA, USA. doi: $10.1145 / 1556460.1556496$

Steinfield, C., Ellison, N., \& Lampe, C. (2008). Social capital, self-esteem, and use of online social network sites: A longitudinal analysis. Journal of Applied Developmental Psychology, 29, 434-445. doi: 10.1016/j.appdev.2008.07.002

Stutzman, F. (2010). Implicit factors in networked information feeds. HCIR 2010. New 
Brunswick, NJ, USA.

Subrahmanyam, K., Reich, S., Waechter, N., \& Espinoza, G. (2008). Online and offline social networks: Use of social networking sites by emerging adults. Journal of Applied Developmental Psychology, 29, 420-433. doi:

10.1016/j.appdev.2008.07.003

Tardiff III, V., Wagner, S., \& Brown, D. (2008). Facebook ${ }^{\mathrm{TM}}$ : The Electronic Dr. Feel-Good. In C. Bonk et al. (Eds.), Proceedings from World Conference on E-Learning in Corporate, Government, Healthcare, and Higher Education 2008, Chesapeake, VA, USA.

Teevan, J., Morris, M. R., \& Panovich, K. (2011). Factors affecting response quantity, quality, and speed for questions asked via social network status messages. ICWSM 2011.

Thadani, D. R., \& Cheung, C. M. K. (2011). Online social network dependency: Theoretical development and testing of competing models. 201144th Hawaii International Conference on System Sciences (HICSS), 1-9.

doi:

10.1109/HICSS.2011.331

Tufekci, Z. (2008). Grooming, gossip, Facebook and Myspace: What can we learn about these sites from those who won't assimilate? Information, Communication \& Society, 11, 544-564. doi: 10.1080/13691180801999050

Valenzuela, S., Namsu, P., \& Kee, K.F. (2009). Is there social capital in a social network site?: Facebook use and college students' life satisfaction, trust, and participation. Journal of Computer-Mediated Communication, 14, 875-901. doi: 10.1111/j.10836101.2009.01474.x

Valenzuela, S., Park, N., \& Lee, K. F. (2008). Lessons from Facebook: The effect of social network siteson college students' social capital. 9th Symposium on Online Journalism, 
Austin, TX, USA.

Valkenburg, P., \& Peter, J. (2007). Preadolescents' and adolescents' online communication and their closeness to friends. Developmental Psychology, 43, 267-277. doi: 10.1037/00121649.43.2.267

Vasalou, A., Joinson, A., \& Courvoisier, D. (2010). Cultural differences, experience with social networks and the nature of "true commitment" in facebook. International Journal of Human-Computer Studies, 68, 719-728.

doi:

10.1016/j.ijhcs.2010.06.002

Vitak, J., Ellison, N. B., \& Steinfield, C. (2011). The ties that bond: Re-examining the relationship between Facebook use and bonding social capital. 2011 44th Hawaii International Conference on System Sciences (HICSS). Kauai, HI, USA. doi: 10.1109/HICSS.2011.435

Wise, K., Alhabash, S., \& Park, H. (2010). Emotional responses during social information seeking on Facebook. Cyberpsychology, Behavior, and Social Networking, 13, 555-562. doi: 10.1089/cyber.2009.0365.

Wohn, D. Y., Lampe, C., Vitak, J. \& Ellison, N. (2011). Coordinating the ordinary: Social information uses of Facebook by adults. Proceedings from the 6th Annual iConference. New York, NY, USA.

Wohn, D. Y., Lampe, C., Wash, R., Ellison, N., \& Vitak, J. (2011). The "S" in social network games: initiating, maintaining, and enhancing relationships. 2011 44th Hawaii International Conference on System Sciences (HICSS), 1-10. doi: 10.1109/HICSS.2011.400

Young, S., Dutta, D., \& Dommety, G. (2009). Extrapolating psychological insights from 
Facebook profiles: A study of religion and relationship status. CyberPsychology and Behavior, 12. doi: 10.1089/cpb.2008.0165.

Young, K. (2011). Social ties, social networks and the Facebook experience. International Journal of Emerging Technologies and Society, 9, 20-34.

Zhang, Y., Tang, L., \& Leung, L. (2011). Gratifications, collective self-esteem, online emotional openness, and traitlike communication apprehension as predictors of Facebook uses. Cyberpsychology, Behavior \& Social Networking, 14, 733-739. doi:10.1089/cyber.2010.0042

Zywica, J., \& Danowski, J. (2008). The faces of facebookers: Investigating social enhancement and social compensation hypotheses; predicting Facebook ${ }^{\mathrm{TM}}$ and offline popularity from sociability and self-esteem, and mapping the meanings of popularity with semantic networks. Journal of Computer-Mediated Communication, 14, 1-34. doi: 10.1111/j.10836101.2008.01429.x

\section{Identity Presentation on Facebook: (50 articles)}

Acar, A. (2008). Antecedents and consequences of online social networking behavior: The case of Facebook. Journal of Website Promotion, 3, 62-83. doi: $10.1080 / 15533610802052654$

Barash, V., Duchenaut, N., Isaacs, E. \& Bellotti, V. (2010). Faceplant: Impression (mis)management in Facebook status updates. Proceedings from ICWSM 2010.

Becker, B.C., \& Ortiz, E.G. (2008). Evaluation of face recognition techniques for application to facebook. International Conference on Automatic Face \& Gesture Recognition. Amsterdam, The Netherlands. 10.1109/AFGR.2008.4813471

Buffardi, L. E., \& Campbell, W. K. (2008). Narcissism and social networking web sites. 
Personality and Social Psychology Bulletin, 34, 1303-1314.

doi:

$10.1177 / 0146167208320061$

Chapsky, D. (2011). Leveraging online social networks and external data sources to predict personality. 2011 International Conference on Advances in Social Networks Analysis and Mining (ASONAM), 428-433. doi: 10.1109/ASONAM.2011.121

DeAndrea, D., Allison S., \& Levine, T. (2010). Online language: The role of culture in selfexpression and self-construal on Facebook. Journal of Language and Social Psychology, Published online before print on August 10, $2010 . \quad$ doi:

10.1177/0261927X10377989

DeWall, C. N., Buffardi, L. E., Bosner, I., \& Campbell, W. K. (2011). Narcissism and implicit attention seeking: Evidence from linguistic analyses of social networking and online presentation. Personality and Individual Differences, 51, 57-62.

DiMicco, J. M., \& Millen, D. R. (2007). Identity management: multiple presentations of self on Facebook. Proceedings from the 2007 International ACM Conference on Supporting Group Work '07. Sanibel Isl., FL, USA.

doi:

$10.1145 / 1316624.1316682$

Egan, K., \& Moreno, M. (2011). Alcohol references on undergraduate males’ Facebook profiles. American Journal of Mens Health, 5, 413-420.

doi: $10.1177 / 1557988310394341$

Evans, D., Gosling, S., \& Caroll, A. (2008). What Elements of an Online Social Networking Profile Predict Target-Rater Agreement in Personality Impressions?. International Conference on Weblogs and Social Media, Seattle, WA, USA. 
Gajaria, A., Yeung, E., Goodale, T., \& Charach, A. (2011). Beliefs about attentiondeficit/hyperactivity disorder and response to stereotypes: Youth postings in Facebook groups. Journal Of Adolescent Health, 49, 15-20. doi:10.1016/j.jadohealth.2010.09.004

García-Gómez, A. (2011). Regulating girlhood: Evaluative language, discourses of gender socialization and relational aggression. European Journal Of Women's Studies, 18, 243264. doi: $10.1177 / 1350506811405817$

Gogolinski, T. B. (2010). Effects of self-monitoring and public self-consciousness on perceptions of Facebook profiles. Colonial Academic Alliance Undergraduate Research Journal, 1 .

Golbeck, J., Robles, C., \& Turner, K. (2011). Predicting personality with social media. Proceedings from CHI EA '11: Annual conference extended abstracts on Human factors in computing systems, 253-262. New York, NY, USA.

Gosling, S. D., Gaddis, S., \& Vazire, S. (2007). Personality impressions based on Facebook profiles. International conference on Weblogs and Social Media, Boulder, CO, USA.

Grasmuck, S., Martin, J., \& Zhao, S. (2009). Ethno-racial identity displays on Facebook. Journal of Computer-Mediated Communication, 15, 158-188. doi: 10.1111/j.1083-6101.2009.01498.x

Hum, N. J., Chamberlin, P. E., Hambright, B. L., Portwood, A. C., Schat, A. C., \& Bevan, J. L. (2011). A picture is worth a thousand words: A content analysis of Facebook profile photographs. Computers In Human Behavior, 27, 1828-1833. doi:10.1016/j.chb.2011.04.003

Karl, K., Peluchette, J., \& Schlaegel, C. (2010). Who's posting Facebook faux pas? A crosscultural examination of personality differences. International Journal of Selection and 
Assessment, 18, 174-186. doi: 10.1111/j.1468-2389.2010.00499.x

Kim, J., \& Lee, J. (2011). The Facebook paths to happiness: Effects of the number of Facebook friends and self-presentation on subjective well-being. Cyberpsychology, Behavior, and Social Networking, 14, 359-364. doi:10.1089/cyber.2010.0374

Kostakos, V., \& Venkatanathan, J. (2010). Making friends in life and online: Equivalence, micro-correlation and value in spatial and transpatial social networks. 2010 IEEE Second International Conference on Social Computing (SocialCom), 587-594. doi:

10.1109/SocialCom.2010.181

Lampe, C., \& Ellison, N. (2010). Student athlete use of Facebook. Proceedings from the 2010 Conference on Computer-Supported Cooperative Work. Savannah, GA, USA. doi: $10.1145 / 1718918.1718954$

Mansson, D. H., \& Myers, S. A. (2011). An initial examination of college students' expressions of affection through Facebook. Southern Communication Journal, 76, 155-168. doi:10.1080/10417940903317710

Mavridis, N., Kazmi, W., Toulis, P., \& Ben-Abdelkader, C. (2009). On the Synergies between Online Social Networking, Face Recognition and Interactive Robotics. International Conference on Computational Aspects of Social Networks. Fontainebleau, France. doi: 10.1109/CASoN.2009.28

Mehdizadeh, S. (2010). Self-presentation 2.0: Narcissism and self-esteem on Facebook. Cyberpsychology, Behavior, and Social Networking, $13 . \quad$ doi: 10.1089/cyber.2009.0257.

Mendelson, A. L., \& Papacharissi, Z. (2009). Look at as: Collective narcissism in college student Facebook photo galleries. In Z. Papacharissi (Ed.), A networked self: Identity, 
community and culture on social network sites. New York: Routledge.

Moreno, M. A., Jelenchick, L. A., Egan, K. G., Cox, E., Young, H., Gannon, K. E., \& Becker, T. (2011). Feeling bad on Facebook: Depression disclosures by college students on a social networking site. Depression And Anxiety, 28, 447-455. doi:10.1002/da.20805

Nazir, A., Raza, S., Chuah, C., \& Schipper, B. (2010). Ghostbusting facebook: detecting and characterizing phantom profiles in online social gaming applications. Proceedings from the 3rd conference on Online social networks (WOSN'10). USENIX Association, Berkeley, CA, USA.

Ong, E., Ang, R., Ho, J., Lim, J., Goh, D., \& Lee, C. (2011). Narcissism, extraversion and adolescents' self-presentation on Facebook. Personality and Individual Differences, 50. doi: 10.1016/j.paid.2010.09.022

Ortigosa, A., Quiroga, J. I., \& Carro, R. M. (2011). Inferring user personality in social networks: A case study in Facebook. 2011 11th International Conference on Intelligent Systems Design and Applications (ISDA), 563-568. doi: 10.1109/ISDA.2011.6121715

Peluchette, J., \& Karl, K. (2008). Social networking profiles: An examination of student attitudes regarding use and appropriateness of content. Cyberpsychology and Behavior, 11, 95-97. doi: $10.1089 / \mathrm{cpb} .2007 .9927$

Peluchette, J., \& Karl, K. (2010). Examining Students’ Intended Image of Facebook: “What Were They Thinking?!”. Journal of Education for Business, 85, 30-37. doi: $10.1080 / 08832320903217606$

Rao, V. (2008). Facebook applications and playful mood: The construction of Facebook as a “third place”. Mindtrek '08. Tampere, Finland.

doi: 
$10.1145 / 1457199.1457202$

Rosenberg, J., \& Egbert, N. (2011). Online impression management: Personality traits and concerns for secondary goals as predictors of self-presentation tactics on Facebook. Journal Of Computer-Mediated Communication, 17, 1-18.

doi:10.1111/j.1083-6101.2011.01560.x

Seder, J., \& Oishi, S. (2011). Intensity of smiling in Facebook photos predicts future life satisfaction. Social Psychological and Personality Science, Published online October 18, 2011. doi: $10.1177 / 1948550611424968$

Sun, T., \& Wu, G. (2011). Traits, predictors, and consequences of Facebook self-presentation. Social Sciences Computer Review, Published online December 7, 2011. doi:10.1177/0894439311425978

Stone, Z., Zickler, T., \& Darrell, T. (2008). Autotagging Facebook: Social network context improves photo annotation. IEEE Computer Society Conference on Computer Vision and Pattern Recognition Workshops, 2008. Anchorage, AK, USA. doi:

10.1109/CVPRW.2008.4562956

Strano, M. (2008). User descriptions and interpretations of self-presentation through Facebook profile images. Cyberpsychology: Journal of Psychosocial Research on Cyberspace, 2.

Stutzman, F. (2007). Impression formation and management in social network websites. ICA 2007. San Francisco, CA, USA.

Tong, S., Van Der Heide, B., Langwell, L., \& Walther, J. (2008). Too much of a good thing? The relationship between number of friends and interpersonal impressions on Facebook. Journal of Computer-Mediated Communication, 13, 531-549. $\quad$ doi: 10.1111/j.1083-6101.2008.00409.x 
Tynes, B., \& Markoe, S. (2010). The role of color-blind racial attitudes in reactions to racial discrimination on social network sites. Journal of Higher Education, 3, 1-13. doi: $10.1037 / \mathrm{a} 0018683$

Underwood, J. M., Kerlin, L., \& Farrington-Flint, L. (2011). The lies we tell and what they say about us: Using behavioural characteristics to explain Facebook activity. Computers In Human Behavior, 27, 1621-1626. doi:10.1016/j.chb.2011.01.012

Varley, C. K. (2011). Perspectives of adolescents with attention-deficit hyperactivity disorder do matter. Journal Of Adolescent Health, 49, 1-2. doi:10.1016/j.jadohealth.2011.05.003

Walther, J., Van Der Heide, B., Kim, S., Westerman, D., \& Tong, S. (2008). The role of friends' appearance and behavior on evaluations of individuals on Facebook: Are we known by the company we keep?. Human Communication Research, 34, 28-49. doi: 10.1111/j.1468-2958.2007.00312.x

Waggoner, A. S., Smith, E. R., \& Collins, E. C. (2009). Person perception by active verses passive perceivers. Journal of Experimental Social Psychology, 45, 1028-1031. doi:10.1016/j.jesp.2009.04.026

Walther, J., Van Der Heide, B., Hamel, L., \& Shulman, H. (2009). Self-Generated Versus Other-Generated Statements and Impressions in Computer-Mediated Communication: A Test of Warranting Theory Using Facebook. Communication Research, 36, 229-254. doi: $10.1177 / 0093650208330251$

Wang, S., Moon, S., Kwon, K., Evans, C., \& Stefanone, M. (2010). Face off: Implications of visual cues on initiating friendship on Facebook. Computers in Human Behavior, 26, 226-234. doi: 10.1016/j.chb.2009.10.001 
Watson, S., Smith, Z., \& Driver, J. (2006). Alcohol, sex, and illegal activities: An analysis of selected Facebook central photos in 50 states. ERIC Document, 493049.

Weisbuch, M., Ivevic, Z., \& Ambady, N. (2009). On being liked on the web and in the 'real world': Consistency in first impressions across personal webpages and spontaneous behavior. Journal of Experimental Social Psychology, 45, 573-576.

doi:10.1016/j.jesp.2008.12.009

Zhao, S., Grasmuck, S., \& Martin, J. (2008). Identity construction on Facebook: Digital empowerment in anchored relationships. Computers in Human Behavior, 24, 1816-1836. doi:10.1016/j.chb.2008.02.012

Zwier, S., Araujo, T., Boukes, M., \& Willemsen, L. (2011). Boundaries to the articulation of possible selves through social networking sites: The case of Facebook profilers' social connectedness. Cyberpsychology, Behavior \& Social Networking, 14, 571-576.

doi:10.1089/cyber.2010.0612

\section{Social Interaction (111 articles)}

Abdul, S., Lin, C., Scholl, J., Fernandez-Luque, L., Jian, W., Hsu, M., \& Li, Y. (2011). Facebook use leads to health-care reform in Taiwan. The Lancet, 377, 2083-2084. doi:10.1016/S0140-6736(11)60919-7

Al Mutawa, N., Al Awadhi, I., Baggili, I., \& Marrington, A. (2011). Forensic artifacts of Facebook's instant messaging service. International Conference for Internet Technology and Secured Transactions (ICITST), 771-776.

Alam, S., Campbell, J., \& Lucas, R. (2011). Using social media in government: The Australian Taxation Office e-Tax Facebook Page. 2011 IEEE Ninth International Conference on 
Dependable, Autonomic and Secure Computing (DASC), 1002-1009. doi:

10.1109/DASC.2011.165

Baran, B. (2010). Facebook as a formal instructional environment. British Journal of Educational Technology, 41, E146-E149. doi: 10.1111/j.1467-8535.2010.01115.x

Binder, J., Howes, A., \& Sutcliffe, A. (2009). The problem of conflicting social spheres: effects of network structure on experienced tension in social network sites. Proceedings from the $27^{\text {th }}$ International conference on Human factors in computing system, Boston, MA. doi: $10.1145 / 1518701.1518849$

Birky, I., \& Collins, W. (2011). Facebook: Maintaining ethical practice in the cyberspace age. Journal Of College Student Psychotherapy, 25, 193-203. doi:10.1080/87568225.2011.581922

Bohert, D., \& Ross, W.H. (2010). The influence of social networking web sites on the evaluation of job candidates. Cybertechnology, Behavior, and Social Networking, 13, 1-7.

Bosch, T. (2009). Using online social networking for teaching and learning: Facebook use at the University of Cape Town. Communicatio: South African Journal of Communication Theory and Research, 35, 185-200.

Bull, S., Breslin, L., Wright, E., Black, S., Levine, D., \& Santelli, J. (2011). Case study: An ethics case study of HIV prevention research on Facebook: The Just/Us Study. Journal Of Pediatric Psychology, 36, 1082-1092. doi:10.1093/jpepsy/jsq126

Butgereit, L. (2011). Dam that social networking: Connecting South Africa's major dams to social media. 2011 6th International Conference on Pervasive Computing and Applications (ICPCA), 11-14. doi: 10.1109/ICPCA.2011.6106470

Caers, R., \& Castelyns, V. (2010). LinkedIn and Facebook in Belgium: The influences and 
biases of social network sites in recruitment and selection procedures. Social Science Computer Review, Published online before print on December 12, 2010. doi:

$10.1177 / 0894439310386567$

Cain, J., Scott, D. R., \& Akers, P. (2009). Pharmacy Students' Facebook Activity and Opinions Regarding Accountability and E-Professionalism. American Journal of Pharmaceutical Education, 73, 104.

Charlton, T., Devlin, M., Marshall, L., \& Drummond, S. (2010). Encouraging interaction and status awareness in undergraduate software engineering projects: The role of social networking services. Education Engineering, Birmingham, UK. doi:

10.1109/EDUCON.2010.5492580

Charnigo, L., \& Barnett-Ellis, P. (2007). Checking out Facebook.com: The Impact of a Digital Trend on Academic Libraries. Information Technology \& Libraries, 26, 23-34.

Chen, H. R., Hwang, J. P., Wu, T. T., Huang, Y. M., \& Hsueh, H. T. (2011). Assessment of implementing a digital game-based learning system over Facebook. 11th IEEE International Conference on Advanced Learning Technologies (ICALT), 621-622. doi: 10.1109/ICALT.2011.191

Chen, W., \& Fong, S. (2010). Social network collaborative filtering framework and online trust factors: A case study on Facebook. Fifth International Conference on Digital Information Management (ICDIM), 266-273. doi: 10.1109/ICDIM.2010.5664676

Chen, Y. (2011). Learning styles and adopting Facebook technology. Proceedings from PICMET '11: Technology Management in the Energy Smart World, 1-9.

Chiang, W. C., Cheng, P. H., Su, M. J., Chen, H. S., Wu, S.W., \& Lin, J. K. (2011). Socio-health with personal mental health records: Suicidal-tendency observation system on Facebook 
for Taiwanese adolescents and young adults. 2011 13th IEEE International Conference on e-Health Networking Applications and Services (Healthcom), 46-51. doi:

10.1109/HEALTH.2011.6026784

Cloete, S., de Villiers, C., \& Roodt, S. (2009). Facebook as an academic tool for ICT lecturers. Proceedings from the 2009 Annual Conference of the Southern African Computer Lecturers' Association (SACLA '09), ACM, New York, NY, USA, 16-22 doi: $10.1145 / 1562741.1562743$

Coe, J., Weijs, C., Muise, A., Christofides, E., \& Desmarais, S. (2011). Teaching veterinary professionalism in the Face(book) of change. Journal of Veterinary Medical Education, $38,353-359$.

Connell, R. (2008). Academic Libraries, Facebook and MySpace, and Student Outreach: A Survey of Student Opinion. Libraries and the Academy, 9, 25-36. doi: 10.1353/pla.0.0036 Connolly, T., Hainey, T., Baxter, G., Stansfield, M., Gould, C., Can, C., Bedir, H., Inozu, J., Tsvetkova, N., Kusheva, R., Stoimenova, B., Penkova, R., Legurska, M., \& Dimitrova, N. (2011). Teachers' views on Web 2.0 in education: An evaluation of a large-scale European pilot. 2011 7th International Conference on Next Generation Web Services Practices (NWeSP), 517-522. doi: 10.1109/NWeSP.2011.6088233

Connolly, T., Hainey, T., Baxter, G., Stansfield, M., Gould, C., Tsvetkova, N., Kusheva, R., Stoimenova, B., Penkova, R., Legurska, M., \& Dimitrova, N. (2011). Web 2.0 education: An evaluation of a large-scale European pilot. 7th International Conference on Next Generation Web Services Practices (NWeSP), 511-516. $\quad$ doi:

10.1109/NWeSP.2011.6088232

Costa, C., \& da Cunha, P. (2010). Who are the players? Finding and characterizing stakeholders 
in social networks. 43rd Hawaii International Conference on System Sciences (HICSS), 110. doi: 10.1109/HICSS.2010.443

Darvell, M., Walsh, S., \& White, K. (2011). Facebook tells me so: Applying the theory of planned behavior to understand partner-monitoring behavior on Facebook. Cyberpsychology, Behavior \& Social Networking, 14, 717-722. doi:10.1089/cyber.2011.0035

DeSchryver, M., Mishra, P., Koehleer, M. \& Francis, A. (2009). Moodle vs. Facebook: Does using Facebook for discussions in an online course enhance perceived social presence and student interaction?. In I. Gibson et al. (Eds.), Proceedings from Society for Information Technology \& Teacher Education International Conference 2009, 329-336. Chesapeake, VA: AACE.

Despotovic-Zrakic, M., Labus, A., \& Milic, A. (2011). Fostering enginering e-learning courses with social network services. $201119^{\text {th }}$ Telecommunications Forum (TELFOR), 122-125. doi: 10.1109/TELFOR.2011.6143508

Dholakia, U. M., \& Durham, E. (2010, March). One café chain's Facebook experiment. Harvard Business Review, 88 .

Elphinston, R. A., \& Noller, P. (2011). Time to face it! Facebook intrusion and the implications for romantic jealousy and relationship satisfaction. Cyberpsychology, Behavior, And Social Networking, 14, 631-635. doi:10.1089/cyber.2010.0318

Emeli, V., \& Christensen, H. (2011). Enhancing the robot service experience through social media. 2011 IEEE RO-MAN, 288-295. doi: 10.1109/ROMAN.2011.6005256

Ermecke, R., Mayrhofer, P., \& Wagner, S. (2009). Agents of Diffusion - Insights from a Survey 
of Facebook Users. 42nd Hawaii International Conference on System Sciences, Honolulu, HI, USA. doi: 10.1109/HICSS.2009.51

Farmer, A. D., Holt, C.E.M.B., Cook, M.J., \& Hearing, S.D. (2008). Social networking sites: a novel portal for communication. Postgrad Med Journal, 85, 455-459. doi: 10.1136/pgmj.2008.074674

Farrow, H., \& Yuan, Y. (2011). Building stronger ties with alumni through Facebook to increase volunteerism and charitable giving. Journal Of Computer-Mediated Communication, 16, 445-464. doi:10.1111/j.1083-6101.2011.01550.x

Ferdig, R., Dawson, K., Black, E., Black, N., \& Thompson, L. (2008). Medical students' and residents' use of online social networking tools: Implications for teaching professionalism in medical education. First Monday, 13.

Fernandes, J., Giurcanu, M., Bowers, K. W., \& Neely, J. C. (2010). The writing on the wall: A content analysis of college students' Facebook groups for the 2008 presidential election. Mass Communication \& Society, 13, 653-675. doi:10.1080/15205436.2010.516865

Fouser, R. (2010). From CMS to SNS: Exploring the use of Facebook in the social constructivist paradigm. 10th IEEE/IPSJ International Symposium on Applications and the Internet (SAINT), 221-224. doi: 10.1109/SAINT.2010.101

Fovet, F. (2009). Impact of the use of Facebook amongst students of high school age with Social, Emotional and Behavioural Difficulties. Frontiers in Education Conference, San Antonio, TX, USA. doi: 10.1109/FIE.2009.5350786

Friggeri, A., Chelius, G., \& Fleury, E. (2011). Triangles to capture social cohesion. 2011 IEEE Third International Conference on Privacy, Security, Risk and Trust (PASSAT), 258-265. doi: 10.1109/PASSAT/SocialCom.2011.169 
Fulton, S., Schweitzer, D., Scharff, L., \& Boleng, J. (2011). Demonstrating the impact of multitasking in the classroom. 2011 Frontiers in Education Conference (FIE), F2J-1-F2J6. doi: 10.1109/FIE.2011.6142991

Gadea, C., Solomon, B., Ionescu, B., \& Ionescu, D. (2011). A collaborative cloud-based multimedia sharing platform for social networking environments. 2011 Proceedings from 20th International Conference on Computer Communications and Networks (ICCCN), 16. doi: 10.1109/ICCCN.2011.6006079

Gallant L. M., Irizarry C., \& Boone G. (2011). Promoting participatory medicine with social media: New media applications on hospital websites that enhance health education and epatients' voice. Journal of Participatory Medicine, 3, e49.

Graffeo, I., \& La Barbera, D. (2009). Cybertherapy meets Facebook, Blogger, and Second Life: An Italian experience. Annual Review of CyberTherapy and Telemedicine, 7, 108-112.

Gray, K., Annabell, L., \& Kennedy, G. (2010). Medical students' use of Facebook to support learning: Insights from four case studies. Medical Teacher, 32, 971-976. doi:10.3109/0142159X.2010.497826

Handayani, P. W., \& Lisdianingrum, W. (2011). Impact analysis on free online marketing using social network Facebook: Case study SMEs in Indonesia. 2011 International Conference on Advanced Computer Science and Information Systems (ICACSIS), 171-176.

Harris, L., \& Dennis, C. (2011). Engaging customers on facebook: Challenges for e-retailers. Journal Of Consumer Behaviour, 10, 338-346. doi:10.1002/cb.375

Hart, J., Ridley, C., Taher, F., Sas, C., \& Dix, A. (2008). Exploring the facebook experience: a new approach to usability. Proceedings from the 5th Nordic Conference on HumanComputer interaction: Building Bridges, Lund, Sweden. doi: 10.1145/1463160.1463222 
Hewitt, A., \& Forte, A. (2006). Crossing boundaries: Identity management and student/faculty relationships on the Facebook. A paper presented at Computer-Supported Cooperative Work, Banff, Alberta, Canada.

Ho, H., \& Pan H. (2010). Use behaviors and website experiences of facebook community. International Conference On Electronics and Information Engineering (ICEIE), Kyoto, Japan. doi: 10.1109/ICEIE.2010.5559855

Honeycutt, C. \& Cunliffe, D. (2010). The use of the Welsh Language on Facebook. Information, Communication \& Society, 13, 226-248. doi: 10.1080/13691180902914628

Ilyas, M. U., \& Radha, H. (2011). Identifying influential nodes in online social networks using principal component centrality. 2011 IEEE International Conference on Communications (ICC), 1-5. doi: 10.1109/icc.2011.5963147

Jovian, L. T., \& Amprimo, O. (2011). OCR correction via human computational game. 2011 44th Hawaii International Conference on System Sciences (HICSS), 1-10. doi: 10.1109/HICSS.2011.319

Juste, P.S., Wolinsky, D., Xu, J., Covington, M., \& Figueiredo, R. (2008). On the Use of Social Networking Groups for Automatic Configuration of Virtual Grid Environments. Grid Computing Environments Workshop, Austin, TX, USA. doi: 10.1109/GCE.2008.4738446

Kamilaris, A., Papadiomidous, D., \& Pitsillides, A. (2011). Lessons learned from online social networking of physical things. 2011 International Conference on Broadband and Wireless Computing, Communication and Applications (BWCCA), 128-135. doi: 10.1109/BWCCA.2011.24

Karl, K., \& Peluchette, J. (2008). Facebook Follies: Who suffers the most? In C. R. Livermore and K. Setzekorn (eds.) Social Networking Communities and eDating Services: Concepts 
and Implications, IGI-Global (Information Science Reference), Hershey, PA, 212-224. doi: 10.4018/978-1-60566-104-9.ch011

Karl, K., \& Peluchette, J. (2011). 'Friending' professors, parents and bosses: A Facebook connection conundrum. Journal Of Education For Business, 86, 214-222. doi:10.1080/08832323.2010.507638

Karl, K., Peluchette, J. \& Schlaegel, C. (2010). Should employees accept their boss's Facebook 'Friend' request?: Examining gender and cultural differences. International Journal of Virtual Communities and Social Networking, 2, 16-30. doi: 10.4018/jvesn.2010070102

Khan, Z., \& Jarvenpaa, S. (2010). Exploring temporal coordination of events with Facebook.com. Journal of Information Technology, 00, 1-14. doi: 10.1057/jit.2010.8

Kim, E.S., \& Han, S.S. (2009). An Analytical Way to Find Influencers on Social Networks and Validate their Effects in Disseminating Social Games. International Conference on Advances in Social Network Analysis and Mining, Athens, Greece. doi: 10.1109/ASONAM.2009.59

Kirschner, P., \& Karpinski, A. (2010). Facebook® and academic performance. Computers in Human Behavior, 26, 1237-1245. doi: 10.1016/j.chb.2010.03.024

Kluemper, D.H., \& Rosen, P.A. (2009). Future employment selection methods: evaluating social networking web sites. Journal of Managerial Psychology, 24, 567-580. doi: $10.1108 / 02683940910974134$

Kostakos, V., \& Venkatanathan, J. (2010). Making friends in life and online: Equivalence, micro-correlation and value in spatial and transpatial social networks. 2010 IEEE Second International Conference on Social Computing (SocialCom), 587-594. doi: 
10.1109/SocialCom.2010.181

Lack, C. W, Beck, L., \& Hoover, D. (2009). Use of Social Networking by Undergraduate Psychology Students. First Monday, 14, 12-7.

Lampe, C., Wohn, D. Y., Vitak, J., Ellison, N. \& Wash, R. (2011). Student use of Facebook for organizing collaborative classroom activities. International Journal of ComputerSupported Collaborative Learning, 6, 329-347.

Lampinen, A., Tamminen, S., \& Oulasvirta, A. (2009). “All My People Right Here, Right Now”: management of group co-presence on a social networking site. Proceedings from the ACM 2009 international conference on Supporting group work (GROUP '09), ACM, New York, NY, USA, 281-290. doi: 10.1145/1531674.1531717

Lawson, T. J., Kleinholz, S. A., \& Bodle, J. H. (2011). Using Facebook to connect alumni, current students, and faculty: A how-to guide. Teaching Of Psychology, 38, 265-268.

Lidstrom, M., Shahan, M., \& Svensson, M. A. (2011). Method for providing content and service recommendations using social information from telecommunications networks. 2011 12th IEEE International Conference on Mobile Data Management (MDM), 1, 321-328. doi: 10.1109/MDM.2011.79

Lyndon, A., Bonds-Raacke, J., \& Cratty, A. D. (2011). College students' Facebook stalking of ex-partners. Cyberpsychology, Behavior \& Social Networking, 14, 711-716. doi:10.1089/cyber.2010.0588

Madge, C., Meek, J., Wellens, J., \& Hooley, T. (2009). Facebook, social integration and informal learning at university: 'It is more for talking to friends about work than for actually doing work'. Learning, Media and Technology, 34, 141-155. doi: $10.1080 / 17439880902923606$ 
Martin, D. L., Allan, J. C., Newton, J., Jones, D. W., Mikulak, S., Mayorga, E., Tanner, T., Lederer, N., Sprenger, A., Blair, R., \& Uczekaj, S. A. (2011). Using web-based and social networking technologies to disseminate coastal hazard mitigation information within the Pacific Northwest component of the Integrated Ocean Observing System. OCEANS 2011, 1-9.

Mavridis, N. (2010). On artificial agents within human social networks: Examples, open questions, and potentialities. International Conference on Digital Ecosystems and Technologies, 685-690. doi: 10.1109/DEST.2010.5610612

Mazer, J., and Murphy, R., \& Simonds, C. (2007). I'll See You on “Facebook": The Effects of Computer-Mediated Teacher Self-Disclosure on Student Motivation, Affective Learning, and Classroom Climate. Communication Education, 56, 1-17. doi: $10.1080 / 03634520601009710$

Mazer, J.P., Murphy, R.E., \& Simonds, C.J. (2009). The effects of teacher self-disclosure via Facebook on teacher credibility. Learning, Media and Technology, 34, 175-183. doi: $10.1080 / 17439880902923655$

Mazman, S., \& Usluel, Y. (2010). Modeling educational usage of Facebook. Computers \& Education, 55, 444-453. doi:_10.1016/j.compedu.2010.02.008

Moubarak, G., Guiot, A., Benhamou, Y., Benhamou, A., \& Hariri, S. (2011). Facebook activity of residents and fellows and its impact on the doctor-patient relationship. Journal of Medical Ethics: Journal Of The Institute Of Medical Ethics, 37, 101-104. doi:10.1136/jme.2010.036293 
Mtibaa, A., \& Harras, K. (2011). Social-based trust in mobile opportunistic networks. 2011 Proceedings from 20th International Conference on Computer Communications and Networks, 1-6. doi: 10.1109/ICCCN.2011.6006047

Naruchitparames, J., Giine, M. H., \& Louis, S. J. (2011). Friend recommendations in social networks using genetic algorithms and network topology. 2011 IEEE Congress on Evolutionary Computation (CEC), 2207-2214.

10.1109/CEC.2011.5949888

Nucleus Research. (2009). Facebook: Measuring The Cost to Business of Social Networking. (Report J57). Boston, MA. Retrieved from http://nucleusresearch.com/research/notesand-reports/facebook-measuring-the-cost-to-business-of-social-notworking/

Ophus, J. D., \& Abbitt, J. T. (2009). Exploring the potential perceptions of social networking systems in university courses. MERLOT Journal of Online Learning and Teaching, 5, 639-648.

Panagiotopoulos, P., Brooks, L., Elliman, T., \& Dasuki, S. (2011). Social networking for membership engagement in non-profit organizations: A trade union study. 17th Americas Conference on Information Systems. Detroit, USA.

Panagiotopoulos, P., Sams, S., Elliman, T., \& Fitzgerald, G. (2011). Do social networking groups support online petitions?. Transforming Government: People, Process and Policy, 5, 20-31.

Pantano, E., Tavernise, A., \& Viassone, M. (2010). Consumer perception of computer-mediated communication in a social network. 4th International Conference on New Trends in Information Science and Service Science, Gyeongju, Korea. 
Ractham, P., \& Firpo, D. (2011). Using social networking technology to enhance learning in higher education: A case study using Facebook. 2011 44th Hawaii International Conference on System Sciences (HICSS), 1-10. doi: 10.1109/HICSS.2011.479

Reich, S. (2010). Adolescents' sense of community on MySpace and Facebook: A mixedmethods approach. Journal of Community Psychology, 38, 688-705. doi: 10.1002/jcop.20389

Robertson, S. P. (2011). Changes in referents and emotions over time in election-related social networking dialog. 2011 44th Hawaii International Conference on System Sciences (HICSS), 1-9. doi: 10.1109/HICSS.2011.97

Roblyer, M.D., McDaniel, M., Webb, M., Herman, J., \& Vince Witty, J. (2010). Findings on Facebook in higher education: A comparison of college faculty and student uses and perceptions of social networking sites. The Internet and Higher Education, 13. doi: 10.1016/j.iheduc.2010.03.002

Rogers, V. L., Griffin, M.Q., Wykle, M. L., \& Fitzpatrick, J. J. (2009). Internet versus face-toface therapy: Emotional self-disclosure issues for young adults. Issues in Mental Health Nursing, 30, 596-602. doi: http://dx.doi.org/10.1080/01612840903003520

Rouis, S., Limayem, M., \& Salehi-Sangari, E. (2011). Impact of Facebook usage on students' academic performance: Role of self-regulation and trust. Electronic Journal of Research in Educational Psychology, 9, 961-994.

Schlagwein, D., \& Prasarnphanich, P. (2011). Organizational social media around the GLOBE. 2011 IEEE Ninth International Conference on Dependable, Autonomic and Secure Computing (DASC), 924-931. doi: 10.1109/DASC.2011.154

Schleyer, T., Spallek, H., Butler, B., Subramanian, S., Weiss, D., Poythress, M., \& 
Rattanathikun, P. (2008). Facebook for scientists: Requirements and services for optimizing how scientific collaborations are established. Journal of Medical Internet Research, 10, 46-59.

Seder, J., \& Oishi, S. (2009). Ethnic/racial homogeneity in college students’ Facebook friendship networks and subjective well-being. Journal of Research in Personality, 43, 438443. doi: $\underline{10.1016 / j . j r p .2009 .01 .009}$

Selwyn, N. (2007). Screw blackboard...do it on Facebook!": An investigation of students' educational use of Facebook." Presented at the "Poke 1.0 - Facebook Social Research Symposium, University of London, London, England.

Selwyn, N. (2009). Faceworking: Exploring students' education-related use of Facebook. Learning, Media and Technology, 34, 157-174. doi: $10.1080 / 17439880902923622$

Skeels, M.M., \& Gruden, J. (2009). When social networks cross boundaries: a case study of workplace use of Facebook and Linkedin. Proceedings from GROUP 2009, Sanibel Island, FL, USA.

Smailes, J., \& Fontainha, E. (2011). Academic adjustment: A pilot to assess the potential of a virtual mentoring scheme. 2011 6th Iberian Conference on Information Systems and Technologies (CISTI), 1-6.

Srba, I., \& Bielikova, M. (2010). Tracing strength of relationships in social networks. International Conference on Web Intelligence and Intelligent Agent Technology, 3, 1316. doi: 10.1109/WI-IAT.2010.241

Sun, E., Rosenn, I., Marlow, C., \& Lento, T. (2009). Gesundheit! Modeling Contagion through Facebook. Proceedings from the Third International Conference on Weblogs and Social 
Media, AAAI Press, San Jose, CA.

Swamynathan, G., Wilson, C., Boe, B., Almeroth, K., \& Zhao, B.Y. (2008). Do social networks improve e-commerce?: a study on social marketplaces. Proceedings from the first workshop on Online social networks, Seattle, WA, USA. doi: 10.1145/1397735.1397737

Sweetser, K. D., \& Weaver L. R. (2008). Candidates make good friends: An analysis of candidates' uses of Facebook. International Journal of Strategic Communication, 2, 175198. doi: $10.1080 / 15531180802178687$

Thaufeeg, A. M., Bubendorfer, K., \& Chard, K. (2011). Collaborative eResearch in a social cloud. 2011 IEEE 7th International Conference on E-Science, 224-231. doi: 10.1109/eScience.2011.39

Thompson, L., Dawson, K., Ferdig, R., Black, E., Boyer, J., Coutts, J., \& Black, N. (2006). The intersection of online social networking with medical professionalism. Journal of General Internal Medicine, 23, 954-7. doi: 10.1007/s11606-008-0538-8

Treepuech, W. (2011). The application of using social networking sites with available online tools for teaching and learning management. 2011 International Symposium on IT in Medicine and Education (ITME), 326-330. doi: 10.1109/ITiME.2011.6130844

Tsaousides, T., Matsuzawa, Y., \& Lebowitz, M. (2011). Familiarity and prevalence of Facebook use for social networking among individuals with traumatic brain injury. Brain Injury, 25, 1155-1162. doi:10.3109/02699052.2011.613086

Viswanath, B., Mislove, A., Cha, M., \& Gummadi, K. P. (2009). On the evolution of user interaction in Facebook. Proceedings from the 2nd ACM Workshop on online Social Networks, Barcelona, Spain. doi: 10.1145/1592665.1592675 
Vitak, J., Zube, P., Smock, A., Carr, C. T., Ellison, N., \& Lampe, C. (2011). It's complicated: Facebook users' political participation in the 2008 election. Cyberpsychology, Behavior, And Social Networking, 14, 107-114. doi:10.1089/cyber.2009.0226

Williams, C. B., \& Gulati, G. J. (2008). The political impact of Facebook: Evidence from the 2006 midterm elections and 2008 nomination contest. Politics \& Technology Review, 1121.

Williams, J. H. (2011). Use of social media to communicate sport science research. International Journal Of Sports Science \& Coaching, 6, 295-300. doi:10.1260/1747-9541.6.2.295

Wills, D., \& Reeves, S. (2009). Facebook as a political weapon: Information in social networks. British Politics, 4, 265-281. doi: 10.1057/bp.2009.3

Woolley, J. K., Limperos, A. M., \& Oliver, M. (2010). The 2008 presidential election, 2.0: A content analysis of user-generated political Facebook groups. Mass Communication \& Society, 13, 631-652. doi:10.1080/15205436.2010.516864

Wu, P., Ding, W., Mao, Z., \& Tretter, D. (2009). Close \& Closer: Discover social relationship from photo collections. IEEE International Conference on Multimedia and Expo, New York, NY, USA. doi: 10.1145/1631272.1631394

Yu, A. Y., Tian, S. W., Vogel, D., \& Kwok, R.C.W. (2010). Can learning be virtually boosted? An investigation of online social networking impacts. Computers \& Education, 55. doi: 10.1016/j.compedu.2010.06.015

Zhang, J. (2010). To play or not to play: an exploratory content analysis of branded entertainment in Facebook. American Journal of Business, 25.

\section{Privacy and Information Disclosure (73 articles)}

Acquisti, A., \& Gross, R. (2006). Imagined Communities: Awareness, Information Sharing and 
Privacy on The Facebook. Proceedings from the 6th Workshop on Privacy Enhancing Technologies, Cambridge, UK. doi: 10.1007/11957454_3

Anthonysamy, P., Rashid, A., \& Greenwood, P. (2011). Do the privacy policies reflect the privacy controls on social networks? 2011 IEEE Third International Conference on Privacy, Security, Risk and Trust, $1158 . \quad$ doi:

10.1109/PASSAT/SocialCom.2011.150

Banks, L., \& Wu, S.F. (2009). All Friends Are Not Created Equal: An Interaction Intensity Based Approach to Privacy in Online Social Networks. International Conference on Computational Science and Engineering, Vancouver, Canada.

Bonneau, J., Anderson, J., Anderson, R., \& Stajano, F. (2009). Eight friends are enough: social graph approximation via public listings. Proceedings from the Second ACM Eurosys Workshop on Social Network Systems, Nuremberg, Germany. doi: $10.1145 / 1578002.1578005$

Bonneau, J., Anderson, J., \& Danezis, G. (2009). Prying Data out of a Social Network. Proceedings from the 2009 international Conference on Advances in Social Network Analysis and Mining, Washington, DC, USA. . doi: 10.1109/ASONAM.2009.45

boyd, d. (2008). Facebook's Privacy Trainwreck; Exposure, Invasion, and Social Convergence. The International Journal of Research into New Media Technologies, 14, 13-20.

boyd, d., \& Hargittai, E. (2010). Facebook privacy settings: who cares? First Monday, 15. doi: $10.1177 / 1354856507084416$

Brandtzæg, P., Luders, M., \& Skjetne, J. (2010). Too many Facebook 'Friends'? Content sharing and sociability versus the need for privacy in social network sites. International Journal of Human-Computer Interaction, 26, 1006-1030. doi: 
$10.1080 / 10447318.2010 .516719$

Bulguru, B., Cavusoglu, H., \& Benbasat, I. (2010). Understanding emergence and outcomes of information privacy concerns: A case of Facebook. International Conference on Information Systems, Paper 230.

Chaulk, K., \& Jones, T. (2011). Online obsessive relational intrusion: Further concerns about Facebook. Journal Of Family Violence, 26, 245-254. doi:10.1007/s10896-011-9360-x

Chen, K., Zhou, Y., Song, L., \& Yang, X. (2011). Building artificial identities in social network using semantic information. 2011 International Conference on Advances in Social Networks Analysis and Mining (ASONAM), 565-566.

doi: 10.1109/ASONAM.2011.33

Christofides, E., Muise, A., \& Desmarais, S. (2009). Information Disclosure and Control on Facebook: Are They Two Sides of the Same Coin or Two Different Processes? Cyberpsychology \& Behavior, 12, 341-345. doi: 10.1089/cpb.2008.0226.

Christofides, E., Muise, A., \& Desmarais, S. (2011). Hey Mom, what's on your Facebook? Comparing Facebook disclosure and privacy in adolescents and adults. Social Psychological and Personality Science. Published online before print May 17, 2011. doi:10.1177/1948550611408619

Chu, H., Deng, D., \& Park, J. (2011). Live data mining concerning social networking forensics based on a Facebook session through aggregation of social data. IEEE Journal on Selected Areas in Communications, 1368-1376. doi:

10.1109/JSAC.2011.110804

Debatin, B., Lovejoy, J. P., Horn, A., \& Hughes, B.N. (2009). Facebook and Online Privacy: Attitudes, Behaviors, and Unintended Consequences. Journal of Computer-Mediated 
Communication, 15, 83-108. doi: 10.1111/j.1083-6101.2009.01494.x

Dwyer, C., Hiltz, S. R., \& Passerini, K. (2007). Trust and privacy concern within social networking sites: A comparison of Facebook and MySpace, Proceedings from AMCIS 2007, Keystone, CO, USA.

Dwyer, C., Hiltz, S., Poole, M., Gussner, J., Hennig, F., Osswald, S., Schliesslberger, S., \& Warth, B. (2010). Developing Reliable Measures of Privacy Management within Social Networking Sites. 43rd Hawaii International Conference on System Sciences (HICSS). doi: 10.1109/HICSS.2010.146

Felt, A., \& Evans, D. (2008). Privacy Protection for Social Networking APIs. Web 2.0 Security and Privacy Conference, Oakland, CA, USA.

Felt, A., Hooimeijer, P., Evans, D., \& Weimer, W. (2008). Talking to Strangers Without Taking Their Candy: Isolating Proxied Content. SocialNets '08, Glasgow, Scotland, United Kingdom. doi: 10.1145/1435497.1435502

Fogel, J., \& Nehmad, E. (2009). Internet social network communities: Risk taking, trust and privacy concerns. Computers in Human Behavior, 25, 153-160. doi:

10.1016/j.chb.2008.08.006

Fuchs, C. (2009). Social Networking Sites and the Surveillance Society. A Critical Case Study of the Usage of studiVZ, Facebook, and MySpace by Students in Salzburg in the Context of Electronic Surveillance. Salzburg/Vienna: Research Group UTI.

Gross, R., \& Acquisti, A. (2005). Information Revelation and Privacy in Online Social Networks. ACM Workshop on Privacy in the Electronic Society, Alexandria, VA, USA. doi: 10.1145/1102199.1102214 
Hameed, S., Xiaoming F., Hui, P., \& Sastry, N. (2011). LENS: Leveraging social networking and trust to prevent spam transmission. 2011 19th IEEE International Conference on Network Protocols, 13-18. doi: 10.1109/ICNP.2011.6089044

Higgins, G., Ricketts, M., \& Vegh, D. (2008). The role of self-control in college student's perceived risk and fear of online victimization. American Journal of Criminal Justice, 33, 223-233. doi: 10.1007/s12103-008-9041-3

Hoadley, C.M., Xu, H., Lee, J.J., \& Rossen, M.B. (2010). Privacy as information access and illusory control: The case of the Facebook News Feed privacy outcry. Electronic Commerce Research and Application, 9, 50-60. doi:10.1016/j.elerap.2009.05.001

Huber, M., Mulazzani, M., Kitzler, G., Goluch, S., \& Weippl, E. R. (2011). Friend-in-the-middle attacks: Exploiting social networking sites for spam. IEEE Internet Computing, 15, 2834.

Ilyas, M. U., Shafiq, M. Z., Liu, A. X., \& Radha, H. (2011). A distributed and privacy preserving algorithm for identifying information hubs in social networks. Proceedings from 2011 IEEE INFOCOM, 561-565. doi:

10.1109/INFCOM.2011.5935226

Jakob, M., Moler, Z., Pechoucek, M., \& Vaculin, R. (2011). Content-based privacy management on the social web. 2011 IEEE/WIC/ACM International Conference on Web Intelligence and Intelligent Agent Technology (WI-IAT), 277-280. doi: 10.1109/WI-IAT.2011.208

Jamal, A., \& Cole, M. (2009). A Heuristic Evaluation of the Facebook's Advertising Tool Beacon. 1st International Conference on Information Science and Engineering, Chennai, India. doi: 10.1109/ICISE.2009.45

Jernigan, C., \& Mistree, B. (2009). Gaydar: Facebook friendships expose sexual orientation. 
First Monday, 14.

King, J., Lampinen, A., \& Smolen, A. (2011). Privacy: Is there an app for that?. Proceedings from the Symposium on Usable Privacy and Security. Pittsburgh, PA, USA. doi: $10.1145 / 2078827.2078843$

Kolek, E., \& Sanders, D. (2008). Online Disclosure: An empirical examination of undergraduate Facebook profiles. NASPA Journal, 45.

Koroleva, K., Brecht, F., Goebel, L., \& Malinova, M. (2011). Facebook - A cognitive calculus model of teenage user behavior on social network sites. Proceedings from the 17th Americas Conference on Information Systems, Paper 392.

Krasnova, H., Gunther, O., Spiekermann, S., \& Koroleva, K. (2009). Privacy concerns and identity in online social networks. Identity Journal Limited 2009, 39-62.

Krasnova, H., Kolesnikova, E., \& Guenther, O. (2009). "It Won't Happen To Me!": SelfDisclosure in Online Social Networks. Proceedings from AMCIS 2009, San Francisco, CA, USA.

Krasnova, H., Spekermann, S., Koroleva, K., \& Hildebrand, T. (2010). Online social networks: Why we disclose. Journal of Information Technology, 25, 109-125. doi: 10.1057/jit.2010.6

Krasnova, H., \& Veltri, N. F. (2010). Privacy calculus on social networking sites: Explorative evidence from Germany and USA. Proceedings from the 43rd Hawaii International Conference on System Sciences, Honolulu, HI, USA. doi: 10.1109/HICSS.2010.307

Lankton, N. K., McKnight, D. H., \& Thatcher, J. B. (2011). The moderating effects of privacy restrictiveness and experience on trusting beliefs and habit: An empirical test of intention 
to continue using a social networking website. IEEE Transactions on Engineering Management,1-12. doi: 10.1109/TEM.2011.2179048

Ledbetter, A. M., Mazer, J. P., DeGroot, J. M., Meyer, K. R., Mao, Y., \& Swafford, B. (2011). Attitudes toward online social connection and self-disclosure as predictors of Facebook communication and relational closeness. Communication Research, 38, 27-53. doi:10.1177/0093650210365537

Lee, R., Nia, R., Hsu, J., Levitt, K. N., Rowe, J., Wu, S. F., \& Ye, S. (2011). Design and implementation of FAITH, an experimental system to intercept and manipulate online social informatics. 2011 International Conference on Advances in Social Networks Analysis and Mining (ASONAM), 195-202. doi:

10.1109/ASONAM.2011.86

Lewis, K., Kaufman, J., \& Christakis, N. (2008). The taste for privacy: An analysis of college student privacy settings in an online social network. Journal of Computer-Mediated Communication, 14, 79-100. doi: 10.1111/j.1083-6101.2008.01432.x

Light, B., \& McGrath, K. (2010). Ethics and social networking sites: A disclosive analysis of Facebook. Information Technology \& People, 23, 290-311. doi: $10.1108 / 09593841011087770$

Lipford, H., Besmer, A., \& Watson, J. (2008). Understanding privacy settings in Facebook with an audience view. Proceedings from the 1st Conference on Usability, Psychology, and Security. San Francisco, CA, USA.

Luo, W., Xie, Q., \& Hengartner, U. (2009). FaceCloak: An Architecture for User Privacy on Social Networking Sites. International Conference on Computational Science and Engineering, Vancouver, Canada. doi: 10.1109/CSE.2009.387 
MacDonald, J., Sohn, S., \& Ellis, P. (2010). Privacy, professionalism and Facebook: A dilemma for young doctors. Medical Education, 44, 805-813. doi: 10.1111/j.13652923.2010.03720.x

Mancini, C., Tomas, K., Rogers, Y., Price, B., Jedrzejczyk, L., Bandara, A., Nuseibeh, B., \& Joinson, A. (2009). From spaces to places: Emerging contexts in mobile privacy. UBICOMP '09: Proceedings from the 11th ACM International Conference, Orlando, FL, USA. doi: 10.1145/1620545.1620547

McKnight, D., Lankton, N., \& Tripp, J. (2011). Social networking information disclosure and continuance intention: A disconnect. 2011 44th Hawaii International Conference on System Sciences, 1-10. doi: 10.1109/HICSS.2011.379

Mo, M., Wang, D., Li, B., Hong, D., \& King, I. (2010). Exploit of online social networks with Semi-Supervised Learning. 2010 International Joint Conference on Neural Networks (IJCNN). doi: 10.1109/IJCNN.2010.5596580

Mohtasebi, A., \& Borazjani, P. N. (2010). Privacy Concerns in Social Networks and Online Communities. Proceedings from VALA2010 Conference, Melbourne, Australia.

Nagle, F., \& Singh, L. (2009). Can Friends Be Trusted? Exploring Privacy in Online Social Networks. International Conference on Advances in Social Network Analysis and Mining, Athens, Greece. doi: 10.1109/ASONAM.2009.61

Nguyen, N., Xuan, Y., \& Thai, M. (2010). A novel method for worm containment on dynamic social networks. Military Communications Conference (MILCOM), 2180-2185. doi: 10.1109/MILCOM.2010.5680488

Nosko, A., Wood, E., \& Molema, S. (2010). All about me: Disclosure in online social networking profiles: The case of FACEBOOK. Computers in Human Behavior, 26, 406- 
418. doi: 10.1016/j.chb.2009.11.012

Osman, F. Y., \& Ab Rahim, N. Z. (2011). Self-disclosure and social network sites users' awareness. 2011 International Conference on Research and Innovation in Information Systems (ICRIIS), 1-6. doi: 10.1109/ICRIIS.2011.6125719

Page, X., \& Kobsa A. (2009). The Circles of Latitude: Adoption and Usage of Location Tracking in Online Social Networking. IEEE International Conference on Computational Science and Engineering, Vancouver, Canada, 1027-1030.

Park, N., Jin, B., \& Jin, S. (2011). Effects of self-disclosure on relational intimacy in Facebook. Computers In Human Behavior, 27, 1974-1983. doi:10.1016/j.chb.2011.05.004

Parris, I., \& Henderson, T. (2011). The impact of location privacy on opportunistic networks. 2011 IEEE International Symposium on a World of Wireless, Mobile and Multimedia Networks, 1-6. doi: 10.1109/WoWMoM.2011.5986149

Patsakis, C., Asthenidis, A., \& Chatzidimitriou, A. (2009). Social Networks as an Attack Platform: Facebook Case Study. Eighth International Conference on Networks, Cancun, Mexico. doi: 10.1109/ICN.2009.77

Ranjbar, A., \& Maheswaran, M. (2011). Community-centric approaches for confidentiality management in online systems. 2011 Proceedings from 20th International Conference on Computer Communications and Networks (ICCCN), 1-6. doi: 10.1109/ICCCN.2011.6005912

Reynolds, B., Venkatanathan, J., Gonçalves, J., \& Kostakos, V. (2011). Sharing ephemeral information in online social networks: Privacy perceptions and behaviours. Proceedings from INTERACT 2011, 3, 204-215. 
Said, H., Yousif, A., \& Humaid, H. (2011). IPhone forensics techniques and crime investigation. 2011 International Conference and Workshop on Current Trends in Information Technology (CTIT), 120-125. doi: 10.1109/CTIT.2011.6107946

Sheldon, P. (2009). "I'll poke you. You'll poke me!" Self-disclosure, social attraction, predictability and trust as important predictors of Facebook relationships . Cyberpsychology: Journal of Psychosocial Research on Cyberspace, 3.

Stutzman, F. (2006). An Evaluation of Identity-Sharing Behavior in Social Network Communities. International Digital and Media Arts Journal, 3.

Stutzman, F., Capra, R., \& Thompson, J. (2011). Factors mediating disclosure in social network sites. Computers In Human Behavior, 27, 590-598. doi:10.1016/j.chb.2010.10.017

Stutzman, F., \& Kramer-Duffield, J. (2010). Friends Only: Examining a Privacy-Enhancing Behavior in Facebook. CHI 2010 Proceedings, Atlanta, GA. doi: $10.1145 / 1753326.1753559$

Tang, C., Wang, Y., Xiong, H., Yang, T., Hu, J., Shen, Q., \& Chen, Z. (2011). Need for symmetry: Addressing privacy risks in online social networks. 2011 IEEE International Conference on Advanced Information Networking and Applications (AINA), 534-541. doi: 10.1109/AINA.2011.57

Taraszow, T., Aristodemou, E., Shitta, G., Laouris, Y., \& Arsoy, A. (2010). Disclosure of personal and contact information by young people in social networking sites: An analysis using Facebook ${ }^{\mathrm{TM}}$ profiles as an example. International Journal of Media \& Cultural Politics, 6, 81-101.

Taraszow, T., Arsoy, A., Shitta, G., \& Laoris, Y. (2008). How much Personal and Sensitive Information do Cypriot Teenagers Reveal in Facebook? Proceedings from 7th European 
Conference on E-Learning, Agia Napa, Cyprus.

Thomas, K., \& Nicol, D. (2010). The Koobface botnet and the rise of social malware. 5th International Conference on Malicious and Unwanted Software (MALWARE), 63-70. doi: 10.1109/MALWARE.2010.5665793

Tufekci, Z. (2008). Can you see me now? Audience and Disclosure Regulation in Online Social Network Sites. Bulletin of Science, Technology, and Society, 28, 20-36. doi: $10.1177 / 0270467607311484$

Waters, S., \& Ackerman, J. (2011). Exploring privacy management on Facebook: Motivations and perceived consequences of voluntary disclosure. Journal Of Computer-Mediated Communication, 17, 101-115. doi:10.1111/j.1083-6101.2011.01559.x

West, A., Lewis, J., \& Currie, P. (2009). Students' Facebook 'friends': public and private spheres. Journal of Youth Studies, 12, 615-627. doi: 10.1080/13676260902960752

Zakaria, N., Lau K. Y., Alias, N. M. A., \& Husain, W. (2011). Protecting privacy of children in social networking sites with rule-based privacy tool. 2011 High Capacity Optical Networks and Enabling Technologies (HONET), 253-257.

doi: 10.1109/HONET.2011.6149828

Zheleva, E., \& Getoor, L. (2009). To join or not to join: The illusion of privacy in social networks with mixed public and private user profiles. 18th International World Wide Web Conference (WWW), Madrid, Spain. doi: 10.1145/1526709.1526781 
Table S2

Number of Articles Published by Category and Year

\begin{tabular}{c|cccccc|c}
\hline Year & $\begin{array}{c}\text { Descriptive } \\
\text { Analysis }\end{array}$ & Motivations & $\begin{array}{c}\text { Identity } \\
\text { Presentation }\end{array}$ & $\begin{array}{c}\text { Social } \\
\text { Interactions }\end{array}$ & $\begin{array}{c}\text { Privacy and } \\
\text { Disclosure }\end{array}$ & TOTALS: \\
\hline 2005 & 0 & 0 & 0 & 0 & 1 & $\mathbf{1}$ \\
2006 & 0 & 3 & 1 & 2 & 2 & $\mathbf{8}$ \\
2007 & 2 & 4 & 3 & 3 & 1 & $\mathbf{1 3}$ \\
2008 & 5 & 13 & 11 & 24 & 9 & $\mathbf{4 8}$ \\
2009 & 6 & 13 & 11 & 25 & 16 & $\mathbf{6 8}$ \\
2010 & 18 & 15 & 18 & 47 & 25 & $\mathbf{8 5}$ \\
2011 & 66 & 31 & $\mathbf{5 0}$ & $\mathbf{1 1 1}$ & $\mathbf{7 3}$ & $\mathbf{4 1 0}$
\end{tabular}

